Article

\title{
Assessment of Temperature and Elevation Controls on Spatial Variability of Rainfall in Iran
}

\author{
Majid Javari \\ Climatology, College of Social Science, Payame Noor University, Tehran 19395-3697, Iran; m_javari@pnu.ac.ir; \\ Tel.: +98-913-328-5930 \\ Academic Editor: Nicole Mölders \\ Received: 23 November 2016; Accepted: 17 February 2017; Published: 6 March 2017
}

\begin{abstract}
With rainfall changes, hydrological process variability increases. This study predicts the potential effects of temperature and topography characteristics on rainfall spatial variability. Temperature and topography were considered as two effective factors that may influence monthly rainfall. This study uses rainfall and temperature data from 174 synoptic and climatic stations and 39,055 rain, elevation and temperature points extracted by ArcGIS10.3 over the 40 years (1975-2014). In this study, in order to predict the relationship between temperature, topography and rainfall, a combination of statistics including spatial statistics and Geographical information System (GIS) methods were employed. It was found that the distribution and rainfall variability in some parts of Iran was regarded to be based on topography and temperature. The spatial patterns showed that the variability based on spatial autocorrelation in rainfall severity gradually increased from west to east and north to south in Iran. Temperature and topography influence rainfall spatial variability; moreover, these factors have direct, indirect and total effects on rainfall variability in temporal and spatial patterns. These research results will be useful for the regionalization of climate and rainfall formation factors, management of water sources, environmental planning and measuring environmental controls on the climate system.
\end{abstract}

Keywords: spatial variability; rainfall variability; spatial autocorrelation

\section{Introduction}

Rainfall is one of the most important variables in the climatic system. Changes in rainfall distribution may lead to bio-environmental issues [1,2]. Rainfall variation can significantly affect the ecosystem and biodiversity. Rainfall patterns have changed significantly in different parts of the globe during the recent decades. Therefore, the variability based on spatial autocorrelation in rainfall effects is important for climate analysis and environmental planning. Environmental change studies have demonstrated that the rainfall amount shows an increase of about $1 \%$ per decade in most of the Northern Hemisphere [3-5]. Global mean precipitation will likely increase by $1 \%-3 \%$ under most scenarios. Climatic models demonstrate that many mid-latitude arid and semi-arid regions will possibly experience less precipitation by the end of the twenty-first century [6]. To predict variability based on spatial autocorrelation in rainfall, different statistics and GIS models have been used. Forecasting methods use variability based on spatial autocorrelation (global and local) in rainfall as an important tool for evaluating the impact of rainfall variability on the climatic systems, because the temporal-spatial formation of global and local spatial autocorrelation-based variability in rainfall remains quite soft and is suitable for environmental studies [7-9]. The global and local variability based on spatial autocorrelation (global and local) in rainfall provides a suitable spatial variability format that computes a rainfall output layer where the value for a rainfall output pixel is a function of the values of the rainfall input point for any station that falls within variability around that station location. 
The global and local spatial autocorrelation performed on the input is a kind of statistics, such as the average and standard deviation of all rainfall values encountered in that station [10]. This paper uses variability based on spatial autocorrelation (global and local) to produce perspectives on the variation in monthly and seasonal precipitation over Iran. Variability based on spatial autocorrelation (global and local) tools creates rainfall output values for each cell station location based on the station value and the values identified in a specified neighborhood [11-13]. The Global and local spatial autocorrelation-based variability tools calculate rainfall output values by using spatial patterns of distribution of stations by considering both their locations and associated correlation values. The point's statistical analysis of monthly rainfall allows to control the cell size and cell alignment of the rainfall output layer, as well as limiting the analysis to specific locations within the analysis extent $[10,14,15]$. The studies on the global and local spatial autocorrelation-based variability in rainfall patterns of different regions in Iran are significant in the context of spatial-regional variability in rainfall. Low precipitation and its severe variations on the monthly and seasonal temporal-spatial scales are the general characteristics of Iran's climates $[16,17]$. The objective of this paper is to spatially analyze and forecast temperature and topography effects on precipitation variability in Iran during the period 1975-2014 utilizing 174 station data and data points' layers. Finally, this paper indicates that few works have been done on the climatology and spatial pattern of monthly, seasonal and annual precipitation in Iran. In the present study, temporal and spatial correlations were measured, in addition to temporal and spatial regressions; global and local spatial autocorrelation analysis and effectiveness of temperatures; and elevation and Digital Elevation Model (DEM) on rainfall using Structural Equation Modeling (SEM). Moreover, effectiveness between monthly, seasonal and annual temperatures, elevation and DEM on rainfall was compared. The effectiveness values between monthly, seasonal and annual temperatures, elevation and DEM on rainfall for regionalization of rainfall were extracted by using ArcGIS. The spatial variability of the variables was analyzed by using the cross-validation technique. In addition, an effort was made to analyze the relationship of the topography effect by indicating the spatial variability in series across the rainfall. Ordinary Least Squares (OLS) and Geographically Weighted Regression (GWR) methods were employed for investigating the relationship between temperatures, topography and rainfall. Two main goals in this study were sought: (1) to calculate, analyze, and forecast the temperature and topography effects on precipitation variability in Iran; and (2) to map and forecast the spatial patterns of monthly precipitation. This paper uses global and local spatial autocorrelation-based variability tools of ArcGIS10.3 to produce perspectives on the variation in monthly, seasonal and annual precipitation over Iran, starting with some general findings and then focusing on the spatial patterns of monthly seasonal and annual rainfall variations and concentration.

\section{Data and Methods}

\subsection{Study Area and Data}

Iran is located between $25^{\circ} 3^{\prime}-39^{\circ} 47^{\prime} \mathrm{N}$ in latitude and $44^{\circ} 5^{\prime}-63^{\circ} 18^{\prime} \mathrm{E}$ in longitude in the south-west of Asia (Figure 1). The total area of Iran is approximately 1,648,195 $\mathrm{km}^{2}$. In general, a year can be divided into two warm and cold seasons [16].

We obtained monthly, seasonal and annual rainfall data for all of Iran's 174 stations from the Meteorological Organization of Iran (http:/ /www.irimo.ir); 39,055 rainfall, temperature and elevation points, have been extracted and the rainfall, temperature and Digital Elevation Model (DEM) layers of Iran were processed by using ArcGIS. Rainfall, temperature and elevation datasets of 174 stations and 39,055 rainfall, temperature and elevation points across Iran were analyzed for the period of 1975-2014 and autocorrelation analysis was applied to the precipitation and temperature time series of each station to check the consistency and the homogeneity [18] in the point statistical analysis by using ArcGIS software. We used homogeneity tests, the Pettitt-Whitney-Mann (PWM), the Standard Normal Homogeneity Test or Alexandersson's SNHT test, Buishand's test, the autocorrelation test $(\mathrm{ACF})$, and the von Neumann test $(\mathrm{VN})$ to explore homogeneity in rainfall time series. The tests were 
applied at $5 \%$ significance level. The results of each homogeneity test are analyzed at a significance level of 0.05 . The results of the tests reveal homogeneity; all the monthly precipitation series are homogeneous [18]. Effects of temperature, elevation and DEM on rainfall were forecasted for the period of 40 years by using AMOS the version number23. For Iran, a Digital Elevation Model (DEM) with $30 \mathrm{~m}$ resolution was used. DEM data were obtained from the https://gdex.cr.usgs.gov/gdex/. Based on the DEM, Iran's elevation values were calculated to predict topography effects on rainfall. In particular, the variability in elevation values across Iran was defined by using geostatistical methods. We used the Inverse Distance Weighted (IDW), Cokriging and Kriging methods [12,15] based on the two-ten nearest stations to interpolate values.

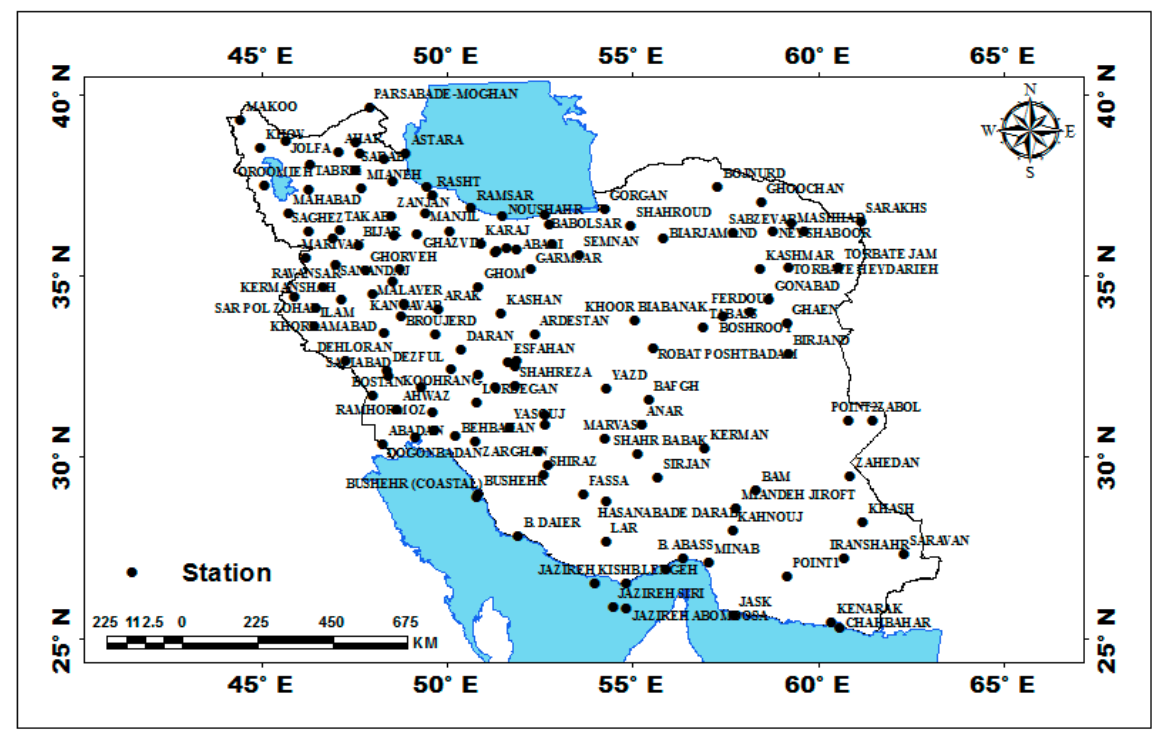

Figure 1. Distribution of Stations.

\subsection{Methodology}

Temperature and rainfall data of 174 stations, 39,055 temperature, rainfall and elevation points from the temperature, and rainfall and DEM layers have been extracted and processed by using ArcGIS across Iran for the period of 1975-2014.

\subsubsection{Interpolation Methods}

Ordinary kriging, as a geostatistical method in ArcGIS software, is used. Ordinary Kriging selected based on the RMSE smaller than the mean error shows smaller prediction error values. Values of RMSE for rainfall (0.813), elevation (0.902) and temperature (0.985) (suggesting spatial prediction of data with acceptable conditions) for the extraction of the estimated values of temperature series, elevation levels and rainfall series at an unmeasured location were on the basis of continuity in space created in its neighborhood. Raster to Point (Conversion) is a spatial analysis method used for the conversion of the estimated values of temperature series, elevation levels and rainfall series to typical point layers on the basis of a data structure created in ordinary kriging. Estimated series of point layers were validated by using cross-validation and validation techniques by validation indicators [19]; mean error (the average difference between the measured and the estimated values) or ME; root mean square error (denotes how closely the model predicts the measured values) or RMSE; average standard error (the average of the prediction standard errors) or ASE; and root mean square standardized error (if the root-mean-squared standardized error is greater than one, the variability in predictions is underestimating) or RMSSE calculated. 


\subsubsection{Correlation Analysis}

In this study, correlations were applied as temporal correlation and spatial correlation. In temporal correlation, the temperature and elevation data were used for correlation with the rainfall data followed by a parametric method for normal distribution (Pearson's correlation coefficient), a non-parametric method for non-normal distribution series (Spearman correlation coefficient) to test the spatial statistical significance of the results. The Spearman correlation coefficient $\left(R_{S}\right)$ is a nonparametric alternative to the Pearson correlation coefficient, which is a parametric test [20]. We used Pearson's correlation coefficient to measure the relationship between rainfall data and the temperature and elevation data for every station. According to Little (2013), the Pearson's correlation coefficient $(R)$ can be calculated using the following equation [21,22]:

$$
R=\sum_{i}\left(X_{i}-\bar{X}\right)\left(Y_{i}-\bar{Y}\right) /(n-1) S_{x} S_{Y}
$$

where $\bar{X}, \bar{Y}, S_{X}, S_{Y}$ are the sample means and standard deviations of $X_{i}, Y_{i}, i=1, \ldots, n$. Correlation coefficients represent dependency between two variables on a standardized scale from -1 to +1 . Although $R$ has many advantages as an effect size, it has the incompatible property, for climatic analysis, of having sample estimates that are skewed around the population mean. According to Little (2013), for climatic analysis, $R$ should be transformed to Fisher's $R_{f}$ prior to the analysis by using the following equation [22,23]:

$$
R_{f}=\frac{1}{2} \ln \left(\frac{1+R}{1-R}\right)
$$

The $R_{f}$ is the Fisher's coefficient and $R$ is the mean effect size $\left(R=\frac{e^{2 R_{f}-1}}{e^{2 R_{f}+1}}\right)$; it is necessary to compute the standard error of the estimation of the effect size $\left(R_{f}\right)$ used in weighting studies on climatic analysis. Considering temperature and elevation effect measurements done at 174 stations and 39,055 temperature and elevation points, the standard error of the estimation of the effect size $\left(R_{f}\right)$ equation is:

$$
S E_{R_{f}}=\frac{1}{\sqrt{N-3}}
$$

$S E_{R_{f}}$ is the standard error. According to Vinzi et al. (2010), in order to compute temperature effect sizes and elevation on rainfall, a wide variety of information reported in studies needed to be used. Although it is not possible to consider all possibilities here, in the remainder of the paper, a few of the more common situations that affect size analysis, using the following equations, will be described [24-27]:

$$
t_{\text {test }}=\frac{P_{\text {sample1 }}-P_{\text {sample } 2}}{\sqrt{\frac{(m-1)^{2}}{(m+n-2)} \times S . E_{\text {sample1 } 1}^{2}+\frac{(m-1)^{2}}{(m+n-2)} \times S . E_{\text {sample2 } 2}^{2} \times \sqrt{\frac{1}{m}+\frac{1}{n}}}} \sim t_{m+n-2}
$$

where, $P_{\text {sample } 1}$ and $P_{\text {sample } 2}$ are the original sample estimate for the path coefficient in both subsamples, $\mathrm{m}$ is the number of cases in sample $1, \mathrm{n}$ is the number of cases in sample 2 and S.E is the standard error of the path coefficients, respectively. The equation $t$-test for computing $R$ through these results is identical to those for computing through dependent sample tests. According to Chin (2000), for climatic significance, analysis should significance $R$ to the $t$-test analysis using the following equation $[26,28]$ :

$$
t_{\text {test }}=\frac{P_{\text {sample } 1}-P_{\text {sample } 2}}{\sqrt{S . E_{\text {sample } 1}^{2}+S . E_{\text {sample2 }}^{2}}}
$$

Spatial correlation between temperature, elevation and rainfall series were evaluated by using the experimental cross-variograms [29]. According to Goovaerts (1997), to compute the spatial correlation of temperature and elevation on rainfall, the fitting of the experimental semi-variogram(s), by using 
some models, should describe the theoretical semi-variogram. These models (spherical, exponential, linear and Gaussian models) provide the spatial correlation patterns of the analyzed rainfall field. In this study, GS + geo-statistics software (Cahn et al. 1994) was used for spatial correlation [30]. In this analysis, the experimental semi-variogram, computed as half of the average squared between the elements of series pairs is applied using the following formula [31-33]:

$$
\hat{\gamma}_{(h)}=\frac{1}{2 N(h)}=\sum_{i=1}^{N(h)}\left[\left(Z_{(S i)}-z(s i+h)\right)\right]^{2}
$$

where $\hat{\gamma}_{(h)}$ is the estimated semi-variance for the distance $h, N(h)$ is the amount of calculated point pairs in the distance session $h$ within the lag distance $h . z(s i)$ and $z(s i+h)$ are the amounts of the variables at two points computed in separated parts by a lag distance $h$.

\subsubsection{Regression Analysis}

In this study, regressions were applied as temporal regressions and spatial regressions. In temporal regressions, the temperature and elevation data were used in a multi-linear regression analysis with the rainfall data followed by the least squares method [20] influence measures to test the temporal statistical significance of the results. Influence measures assess to what extent the modification of a particular condition will change the rainfall of estimated values and regression coefficients; that is, whether the condition affects the results and conclusions through the regression analysis. Multi-linear regression [34] has measures of influence. According to Hino et al. (1979), the temporal regression model can be calculated using the following equation [1,35-37]:

$$
Y_{t}=\beta_{0}+\beta_{1} x_{1}+\beta_{2} x_{2}+\ldots \beta_{n} x_{n}+\varepsilon_{t}
$$

where $Y_{t}$ is an estimate, $\beta_{0}$ and $\beta_{1}$ are the regression coefficients, $x$ is the independent variable and $\varepsilon_{t}$ is the error term. Spatial regressions have been used for quite some time in climatic analysis as explanatory models. Spatial regression techniques, established by Luc Anselin et al. (1998), describe spatial dependency [38] in series [39]. Spatial regression [40] is a type of the regression model using a proximity matrix or geographic weight matrix in which the neighborhood series about the spatial zones are considered and estimated for spatial autocorrelation. Regression analysis was applied to explore the spatial relationships and observed spatial patterns. According to Woody (2015), the spatial regression model can be calculated using the following equation [35]:

$$
Y_{t}=\sum_{h}^{k} x h \beta_{h}+\varepsilon_{t}
$$

where $\beta_{h}$ is the associated regression coefficient and $\varepsilon_{t}$ is an error term. In addition, for spatial modelling of variable effectiveness on the rainfall, the ordinary least squares (OLS) regression was applied, with three special characters: (i) the valuation and plotting of the spatial pattern in typical errors; (ii) regression analysis, using nth order polynomial extension of geographical coordinates; and (iii) the calculation of the Akaike Information Criterion (AIC) for the evaluation of model fit. In this study, a local form of linear regression was applied to model spatially varying effectiveness as a Geographically Weighted Regression (GWR) method. GWR constructs these separate equations by combining the dependent and explanatory variables of patterns falling within the bandwidth of each affected pattern. The shape and size of the bandwidth is dependent on data for the Kernel type, Bandwidth method, Distance, and Number of neighbor's parameters. To analyze the OLS and GWR, both the Joint F-Statistic and Joint Wald Statistic are measures of overall model statistical significance. The Joint F-Statistic (tests the normality of the errors) is trustworthy only when the Koenker (BP) statistic is not statistically significant. If the Koenker (BP) statistic is significant, you should consult the Joint Wald Statistic to determine the overall model significance. The null hypothesis 
for both of these tests indicates that the explanatory variables in the model are not effective. For a 95\% confidence level, a $p$-value (probability) smaller than 0.05 indicates a statistically significant model. Results obtained from a specified OLS model are reliable, such as those obtained from R-Squared and Akaike's Information Criterion (AICc) measure fit/performance model and Joint $\mathrm{F}$ and Wald Statistics. Asterisk $(*)$ indicates the overall model significance $(p<0.01)$; if the Koenker (BP) Statistic is statistically significant, use the Wald Statistic to determine the overall model significance. Koenker (BP) Statistic: When this test is statistically significant $(p<0.01)$, the relationships modeled are not consistent (due to non-stationary); use Wald Statistic to determine the overall model significance. Jarque-Bera Statistic: when this test is statistically significant $(p<0.01)$, model predictions are biased (the residuals are not normally distributed). Bandwidth or Neighbors is the number of neighbors used for each local estimation and is perhaps the most important parameter for Geographically Weighted Regression. It controls the degree of smoothing in the model. Residual Squares is the sum of the squared residuals in the model with the GWR model. The smaller this measure, the closer the fit of the GWR model to the observed data. This value is used in a number of other diagnostic measures. The Effective Number value reflects an interchangeability between the variance of the fitted values and the bias in the coefficient estimates and is related to the choice of bandwidth.

\subsubsection{Global and Local Spatial Autocorrelation Analysis}

There are a number of different definitions of spatial autocorrelation to evaluate the spatial patterns of the temperature effect sizes and the elevation on rainfall. According to Cai et al. (2006), to determine spatial autocorrelation analysis in climate, especially to evaluate the relationship between climatic factors and rainfall, both their locations and relationships values are considered. In global and local spatial autocorrelation analysis of temperature effect sizes and elevation on rainfall, contiguity needs to be measured. In this study, the global and local spatial autocorrelation-based variability methods were used to calculate the effects of temperature and topography on rainfall at the studied stations. The global and local spatial autocorrelation-based variability was presented by the Esri as a method to estimate rainfall spatial variation patterns. The global and local spatial autocorrelation tool measures spatial autocorrelation based on both station locations and station values simultaneously $[10,41,42]$. The spatial relationship between the temperature, topography, and rainfall variables in Iran was statistically examined. Spatial autocorrelation has different aspects and it is most commonly expressed with the spatial relationships and distribution patterns of climatic elements. Spatial autocorrelation is measured based on station locations and climatic element values by using the global and local statistics. This index uses a measure of the spatial autocorrelation coefficient to measure and determine how temperature and rainfall along with elevation locations are clustered, dispersed and randomized in space regarding the correlation between temperature, elevation and rainfall values in Iran [43-45]. With temperature and elevation spatial autocorrelation effect measurements done at 174 stations and 39,055 temperature and elevation points, Moran's I of the estimation of the effect size (I) equation is: [45-48]:

$$
I=\frac{N}{S_{0}} \frac{\sum_{i=1}^{N} \sum_{j=1}^{N} W_{i j} Z_{i} Z_{j}}{\sum_{i=1}^{N}\left(Z_{i}\right)^{2}}
$$

where $N$ is the number of stations, $Z_{i}$ and $Z_{j}$ are the deviation of variables from its mean, $W_{i j}$ is the spatial weight of spatial locations $i$ and $j$ and

$$
S_{0}=\sum_{i=1}^{N} \sum_{j=1}^{N} W_{i j}
$$

The value of Moran's $I$ varies between -1 and 1 . The value of Moran's $I$ near +1 indicates clustering of the rainfall and the value near to -1 indicates the dispersed pattern of the rainfall and 
the value near to 0 indicates the random pattern of the rainfall. The statistical significance of spatial autocorrelation can be measured by $z$-statistics, which is calculated as follows [10]:

$$
Z_{I}=I-E[I] / \sqrt{V[I]}
$$

where:

$$
\begin{aligned}
E[I] & =-1 /(N-1) \\
V[I] & =E[I]^{2}-E[I]^{2}
\end{aligned}
$$

where $E(I)$ and $V(I)$ denote the expected amount and the variance of Moran's I respectively, and $V[I]$ represents variance of I. However, the spatial autocorrelation analysis returns five values: the Moran's I Index, the expected index, variance, $Z$-score, and $p$-value. The z-scores and $p$-values were returned by the pattern analysis method and provided the null hypothesis to be confirmed or rejected. When the $p$-value is very small, it means that there is little probability that the observed spatial pattern is the result of random processes, so the null hypothesis can be rejected. If the $p$-value is not statistically significant, the null hypothesis is not rejected. It is quite possible that the spatial distribution of observed values is the result of random spatial processes. However, if the positive results of Moran's I statistic with significant p-values and high Z-scores reveal spatially clustered data series. Simultaneously, negative Moran's I statistic shows that the variability pattern is more spatially dispersed [10,49]. Nevertheless, Moran's I is a general statistic index that shows the amount of autocorrelation in the analysis. When data correlation is spatially significant, it is important to compute local spatial autocorrelation indices. The Getis-Ord Gi statistics provide the statistical probability of clusters of climatic elements having a higher (hot spot) or lower (cold spot) distribution than what would be expected by random values [50,51]. The distribution similarities in temperature and elevation amounts on rainfall were estimated by using Getis-Ord Gi statistics in each station instead of measuring rainfall frequency. The Getis-Ord Gi statistics are calculating the degree of clustering for either high values or low values. According to ESRI (2014), for local spatial autocorrelation analysis, Getis-Ord Gi statistics should be used via the following equation:

$$
\begin{gathered}
G_{i}^{*}=\frac{\sum_{j=1}^{N} w_{i, j} X_{j}-\bar{X} \sum_{j=1}^{N} w_{i, j}}{S \sqrt{\left[\frac{\left.N \sum_{j=1}^{N} w_{i, j}^{2}-\left(\sum_{j=1}^{N} w_{i, j}\right)^{2}\right]}{N-1}\right]}} \\
S=\sqrt{\frac{\sum_{j=1}^{N} x_{j}^{2}}{N}-(\bar{X})^{2}} \\
\bar{X}=\frac{\sum_{j=1}^{N} x_{j}}{N}
\end{gathered}
$$

where, $x_{j}$ is the variable value for station $j, w_{i, j}$ is the spatial weight between stations $i$ and $j$, and $\mathrm{N}$ is the total number of stations. The Getis-Ord Gi statistics are inferential, which means that the results of the analysis are interpreted in relation to the null hypothesis. If the $p$-value is not statistically significant, the null hypothesis is not rejected. It is quite possible that the distribution of the observed values is the result of random spatial processes. If the $p$-value is statistically significant, and the $z$-score is positive, the null hypothesis is rejected. It is quite possible that the distribution of high values in the dataset is more spatially clustered and if the $p$-value is statistically significant, and the $z$-score is 
negative, the null hypothesis is rejected. It is quite possible that the spatial distribution of low values in the data is more spatially clustered. The distribution of high values and low values in the data is more spatially dispersed [52-54]. Considering spatial clustering in the dataset, it is necessary to mention both their location and distance values. We estimated, for distance associated with spatial autocorrelation between temperature and elevation, the amounts and their effects on rainfall by using incremental spatial autocorrelation statistics in each station. Measures of spatial autocorrelation for a series of distances necessarily create a trend of those distances and their corresponding $z$-scores. $Z$-scores reflect the intensity of spatial clustering and statistically significant maximum $z$-scores indicate distances where spatial processes are an expanded clustering process $[47,55]$. The incremental spatial autocorrelation statistics apply the Global Moran's index for a dataset of increasing distances and measure the agglomeration of spatial clustering for each distance. The intensity of clustering is determined by the related z-score. Eventually, as the distance increases, the z-score increases too, indicating the increase of clustering. At certain distance, the $z$-score generally is maximum [10].

\subsubsection{SEM-PLS-GIS Method}

Structural Equation Modeling (SEM) is a statistical method that takes a confirmatory approach to the analysis of a structural theory effect on climatic changes. In order to identify the linear and non-linear relationships, SEM was applied within each climatic series and then compared these relationships across climatic areas in order to predict the interacting relationship between these effects within each climatic pattern separately. After extracting rainfall, temperature and elevation series, the maximum likelihood (ML) method in the SEM was applied. SEM was used to analyze some typical characteristics, including (1) providing a structure for studying causal processes [56]; (2) forecasting the assessment of direct and indirect effects [57]; and (3) providing a review of the causal processes in climatic analysis [58]. It was assumed that elevations, DEM and temperature series have a direct effect on rainfall series. In addition, it was assumed that elevations, DEM and temperature series have an indirect effect on rainfall. Since elevation and DEM have a direct effect on temperature and temperature has a direct effect on rainfall, the relationship between elevation and DEM can also be estimated through an indirect effect. The indirect effect related between elevation and DEM was analyzed by using variation patterns of the related temporal-spatial controls. After all, the total effect can be estimated as the amounts of the direct and indirect effects between elevation, DEM and temperature. This paper provides a simple pattern of the Partial Least Squares (PLS) method [59]. PLS was applied to analyze the linear relationships [60] between multiple independent variables (temperature, elevation and DEM) and a dependent variable (rainfall). The direct and indirect effects related between elevation and DEM was extracted using the ordinary kriging and was estimated as the amounts of the direct and indirect effects between elevation, DEM temperature and rainfall (SEM-PLS-GIS). However, a new SEM method is proposed based on SEM-PLS-GIS, which combines the principles of the SEM measurement model and the PLS, SEM structural model [61] and PLS [62], and spatial trend analysis by GIS. Thus, the new mathematical model can not only generate factors to form a structural model but also ensures the optimum relationship to the objective dependent variables. By using the SEM-PLS-GIS method and spatial relationships, spatial trend analysis and prediction of the temperature and elevation effects on precipitation have been done. The method consists of three components: measurement model, structural model [63] and spatial model [64]. In this method, direct effects represent the relationship between one latent variable to another. Indirect effects reflect the relationship between an independent latent variable (exogenous variable) and a dependent latent variable (endogenous variable) that are mediated by one or more latent variables. The total effect is the sum of the direct and indirect effects. Generally, there are two different ways to measure latent variables. One approach is referred to as reflective measurement, and the other is called formative 
measurement. According to Azar et al. (2012), reflective measurement can be used to analyze the temperature and elevation effects on rainfall by using the following equation [65]:

$$
X_{h}=\pi_{h o}+\pi_{h} \xi+\varepsilon_{h}
$$

where $X_{h}$ is the observed variable, $\xi$ is the non-dependent latent variable, $\pi_{h 0}$ is the loading associated to the $p$-th manifest variable in the $q$-th block and $\varepsilon_{h}$ is the imprecision in the measurement process. Equation (17) is called the reflective method in PLS where $\xi$ is the general endogenous latent variable and $\varepsilon$ is the error. The structural model should be used to analyze the temperature and elevation effects on rainfall by using the following equation $[65,66]$ :

$$
\xi_{i}=\beta_{j o}+\sum \beta_{i j} \xi_{i}+\xi_{j}
$$

where $\beta_{j o}$ is the constant coefficient interrelating the $q$-th exogenous latent variable to the $j$-th endogenous one, $\beta_{i j}$ is the general path coefficient interrelating the $q$-th exogenous latent variable to the $j$-th endogenous one, $\xi_{j}$ is the error in the inner relation. SEM analyzes the temperature and elevation effects on rainfall by using two components: the structural model and the measurement model; PLS forecasts the temperature and elevation effects on rainfall by using three components: the structural model, the measurement model, and the weighting scheme; GIS analyzes the temperature and elevation effects on rainfall using two components: the spatial and temporal models.

\subsubsection{Statistical Significance of Effectiveness}

One of the test statistics in the models is the critical ratio (C.R.), which represents the parameter estimate divided by its standard error; as such, it operates as a $z$-statistic in testing that the estimate is statistically different from zero $[66,67]$. Based on a probability level of 0.05 , then, the test statistic needs to be $> \pm 1.96$ before the hypothesis can be rejected. In the model summary presented in this study, it was observed that AMOS software provided the overall chi-square $\left(X^{2}\right)$ value, together with its degrees of freedom and probability value. However, it is essential that we first review four important aspects of fitting hypothesized models; these are (1) the model fitting; (2) the result of statistical significance; (3) the estimation stages; and (4) the goodness-of-fit indexes [5,57,66]. Goodness-of-fit indexes were used in this study. Hence, absolute fit indices (AFI), comparative fit indices (CFI) and parsimonious fit indices (PFI) were considered. The comparative fit index is based on comparing the model with competitor models and the parsimonious fit index is dependent on the desired parameters of the researcher. Absolute fit indices include the chi-square index (X2), the goodness-of-fit index (GFI), the adjusted goodness-of-fit index (AGFI) and root mean squared residual (RMR), (Fernando Gutierrez, 2014). The comparative or relative fit index includes the Tucker-Lewis index (TLI), the Bentler-Bonnet index (NFI), the comparative fit index (CFI), the relative fit index (RFI), and the incremental fit index (IFI). Parsimonious fit indices include normed chi-square (NC), parsimony ratio (PRATIO), the parsimonious normed fit index (PNFI), the parsimonious goodness-of-fit index (PGFI), root average squared error of approximation (RMSEA) and normed chi-square (CMIN/DF). To compare the models, Akaike information criterion indices (AIC), Browne-Cudeck criterion (BCC), Bayes information criterion (BIS), consistent version of Akaike information criterion (CAIC), non-central parameter (NCP), Hoelter non-central parameter (NCP), Hoelter's index, (HOELTER), the expected cross validation index (ECVI) and the modified expected cross-validation index (MECVI) are used.

\section{Results and Discussion}

\subsection{Temperature and Rainfall Properties}

Temperature is one of the most important elements of Iran's and global climate. Usually, the temperature is considered as a climatic element difference between south and north parts of Iran. It has a considerable impact on rainfall distribution in Iran. The maximum rainfall occurs on 
the southwest of the Caspian Sea, in the northwest on the western slopes of the Zagros Mountains around Sanandaj and Ravansar meteorological stations, and on the southern slopes of the southern Zagros Mountains around the Baft station. Annual rainfall varies from more than $1800 \mathrm{~mm}$ in Bandar Anzali to below $55 \mathrm{~mm}$ (Figure 2) at the Bafgh station [17]. The interior parts of Iran receive much less precipitation. Approximately $94.8 \%$ of Iran is arid or semi-arid with low atmospheric precipitation $[16,68]$. More than half of Iran receives less rainfall than $200 \mathrm{~mm}$ and some parts get less rainfall than $35 \mathrm{~mm}$ annually. Seasonal rainfall variations related to Iran's subtropical system position are added to this variability [69]. More than half of the annual rainfall is in winter from westerly systems carrying Mediterranean Sea moisture [17,70,71].

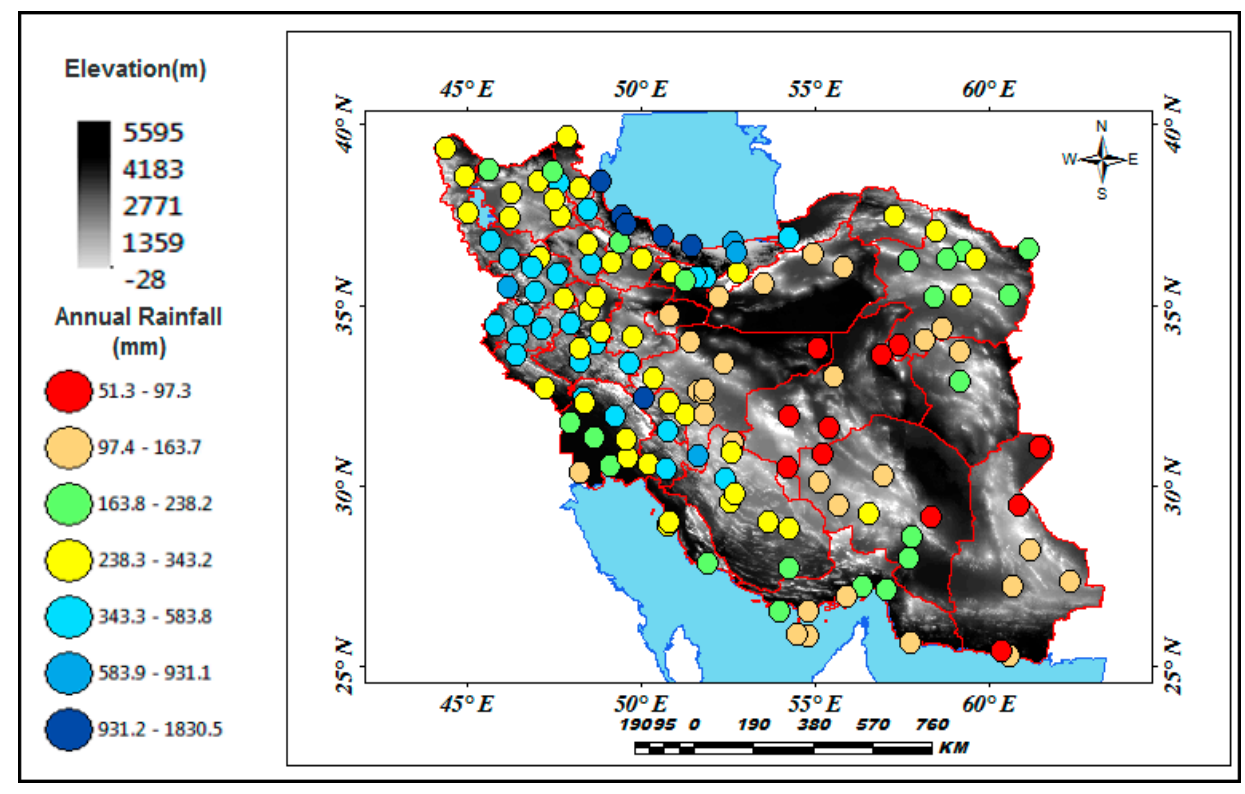

Figure 2. DEM and rainfall distribution in Iran.

Figure 3 shows the annual temperature distribution of 39,055 rainfall and temperature points in Iran. On annual scales, since the last decades, the highest temperature has been in southern regions toward the central parts of Iran. This temperature difference is distributed irregularly in Iran, especially during summer. Three types of temperature effects on rainfall are distinguished: direct, indirect and total. During the direct type, temperature on rainfall is one directional; in the indirect type, it is multi-directional; and in the total type, it has both direct and indirect effects. Moreover, the relationships between each measure of temperature and precipitation were explored as primary analyses showed different relationships within temperature factors. When analyzing the effect of factors on precipitation, the rate of this impact was studied. To assess the relative importance of direct, indirect and total effects of temperature on precipitation, standardized and non-standardized coefficients were compared. By estimating factor score weights, the capability of each variable in predicting the studied series was revealed. Through estimating the threshold ratio or critical ratio for the difference between the factors, other factors were carefully compared. As for the temperature variables, we used the calculated minimum temperature, which was found to be the best predictor of precipitation among temperature factors [64]. 


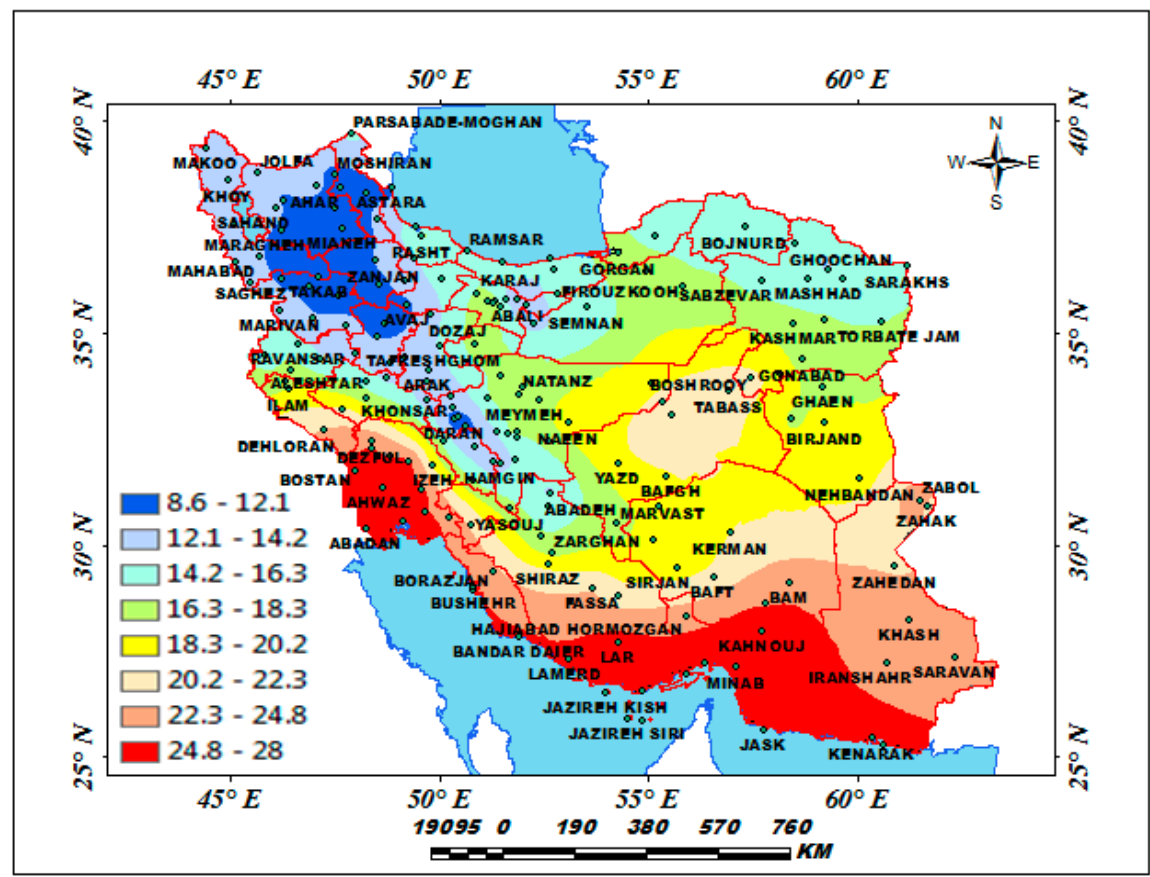

Figure 3. Distribution of annual temperature.

\subsection{Elevation Distribution}

To predict the relationship between topography and rainfall, for Iran, a digital elevation model with $30 \mathrm{~m}$ resolution was used. DEM data was extracted from the https:/ / earthexplorer.usgs.gov. Topographic changes and the mid-slopes were estimated from the Extracted DEM to measure terrains elevation levels. The elevation distribution of Iran varies from -28 to $5595 \mathrm{~m}$ above sea level. The area is characterized by diverse rainfall patterns with a point range annual rainfall of about $50-1831 \mathrm{~mm}$ (Figure 2). For DEM, the correlation coefficient was calculated for rainfall to provide a relationship between rainfall and elevation. The spatial distribution of the elevations was analyzed by DEM. Assessing the effect of the elevation levels on rainfall for Iran demonstrated that rainfall variability is negatively related to elevation. Topographically, almost the entire domain of Iran (85\%) is disturbed by various elevation levels. The west of Iran is denominated by a domain of mountains with elevation levels in the direction of northwest to southeast. The eastern part of the country is not subjected to elevation influences. Temperature over Iran varies spatially and the annual temperature mean for the whole of Iran is $19.4{ }^{\circ} \mathrm{C}$ above the forecasted period in 39,055 temperature points and 174 stations (Figure 3). The distribution of temperature decreases with altitude and latitude towards the west and northwest of Iran. Rainfall over Iran varies spatially and the annual rainfall for the whole of Iran has the range of $1730 \mathrm{~mm}$ over the forecasted period in 39,055 rainfall points and 174 stations (Figure 4). The distribution of rainfall decreases with a certain altitude towards the west and north of Iran $[17,72]$. The southwest of the Caspian Sea and western mountains regions received a maximum of 1143-1760 $\mathrm{mm}$ of rainfall, whereas the southeast and central parts received about 30-91 mm annually. Most of Iran's mountainous parts have the maximum rainfall amount in winter and the minimum rainfall amount in summer. 


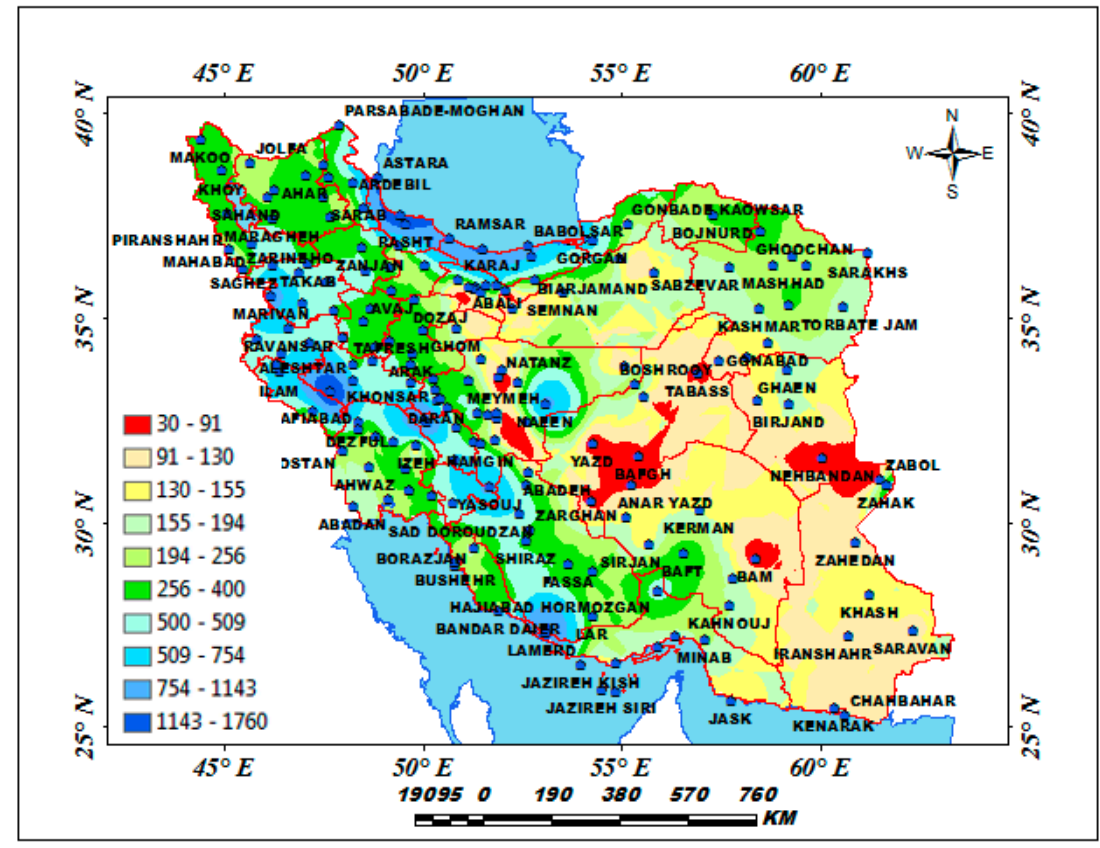

Figure 4. Distribution of Annual Rainfall.

\subsection{Statistical Analysis of Data Properties}

The statistical properties of original and estimated series revealed the various estimated distributions of data (Table 1). According to the results of the statistical properties of original and estimated series, considerable similarities were shown. Mean values of the data series, original and estimated rainfall studied in Iran were $322.8 \mathrm{~mm}$ and $313 \mathrm{~mm}$, respectively. Mean values of the data series for the original and estimated temperature series calculated in Iran were $17.8{ }^{\circ} \mathrm{C}$ and $17.61{ }^{\circ} \mathrm{C}$, respectively. Mean values of the data series, original and estimated elevation studied in Iran were $1053.4 \mathrm{~m}$ and $1139.4 \mathrm{~m}$, respectively. The results of this analysis indicated that the described values of statistical properties for original and estimated series conformed considerably in 40 periods. In the series statistical properties examined, predicated rainfall showed a maximum variation $(\mathrm{RSD}=99.01 \%)$, while the variability of predicated elevation $(\mathrm{RSD}=54.32 \%)$ was minimum. In relation to the analysis of relative standard deviation, rainfall series showed a strong variability whereas temperature showed a modest variability and elevation showed a weak variability.

Table 1. Statistical properties of original and estimated series.

\begin{tabular}{cccccc}
\hline Variables & Mean & $\begin{array}{c}\text { Standard } \\
\text { Deviation (SD) }\end{array}$ & $\begin{array}{c}\text { Relative Standard } \\
\text { Deviation \% (RSD) }\end{array}$ & Minimum & Maximum \\
\hline Annual temperature & 17.8 & 5.37 & 30.1 & 8.60 & 28.60 \\
Estimated temperature & 17.61 & 4.93 & 27.9 & 8.54 & 27.97 \\
Annual rainfall & 322.8 & 280.2 & 91 & 51.3 & 1830.5 \\
Estimated rainfall & 313 & 218.9 & 69.9 & 0.0 & 1496.2 \\
Elevation & 1053.41 & 697.98 & 62.76 & -23.6 & 6105 \\
Estimated elevation & 1139.44 & 619 & 54.32 & -22.8 & 5595 \\
\hline
\end{tabular}

We forecasted our analysis hypotheses by computing the coefficient of variations of the effect of temperature, elevation and rainfall of 174 stations.

\subsection{Selection of Interpolation Method}

For regionalization, the rainfall and temperatures variation patterns estimated the cross-validation of predicated series. The cross-validation of predicated series revealed RMSSE values for ordinary 
kriging (Table 2) closer to zero, showing that the ordinary kriging method is suitable to predict the spatial variability. RMSE values of simple kriging for summer temperature (2.31) were smaller than the ordinary kriging methods (Table 2), revealing that the spatial variability prediction of summer temperature is suitable using simple kriging.

Table 2. The cross-validation of estimated series.

\begin{tabular}{|c|c|c|c|c|c|c|c|c|c|c|c|c|}
\hline \multirow{2}{*}{ Series } & \multicolumn{3}{|c|}{ ME } & \multicolumn{3}{|c|}{ RMSE } & \multicolumn{3}{|c|}{ ASE } & \multicolumn{3}{|c|}{ RMSSE } \\
\hline & OK & SK & IDW & OK & SK & IDW & OK & SK & IDW & OK & SK & IDW \\
\hline Annual Temperature & -0.1 & -0.13 & -0.17 & 2.13 & 2.205 & 3.11 & 2.46 & 2.89 & 3.54 & 0.985 & 0.996 & 2.01 \\
\hline Winter temperature & -0.09 & -0.06 & -0.12 & 2.1 & 2.24 & 2.36 & 2.62 & 3.46 & 3.67 & 0.88 & 0.73 & 1.04 \\
\hline Spring temperature & -0.06 & -0.14 & -0.211 & 2.32 & 2.386 & 2.63 & 2.94 & 2.89 & 3.15 & 0.798 & 0.93 & 0.976 \\
\hline Summer temperature & -0.02 & -0.17 & -0.21 & 2.4 & 2.31 & 2.46 & 3.13 & 2.38 & 3.42 & 0.77 & 1.65 & 1.73 \\
\hline Autumn temperature & -0.01 & -0.028 & -0.031 & 2.11 & 2.29 & 3.11 & 2.77 & 3.66 & 3.86 & 0.78 & 0.66 & 0.96 \\
\hline Elevation & 16.15 & 34.94 & 38.34 & 375.25 & 379.36 & 385.6 & 194.46 & 494.5 & 499.54 & 0.902 & 0.93 & 1.32 \\
\hline Annual Rainfall & -2.97 & -9.8 & -11.4 & 170.67 & 197.46 & 203.3 & 241.38 & 192.86 & 253.1 & 0.813 & 0.84 & 0.97 \\
\hline
\end{tabular}

OK = Ordinary kriging, SK = Simple kriging and IDW = Inverse distance weighted interpolation.

Figure 5 shows the variability of temperature for all 174 stations in the increasing annual period $(21 \%-67 \%)$ from northwest to south and southeast Iran.

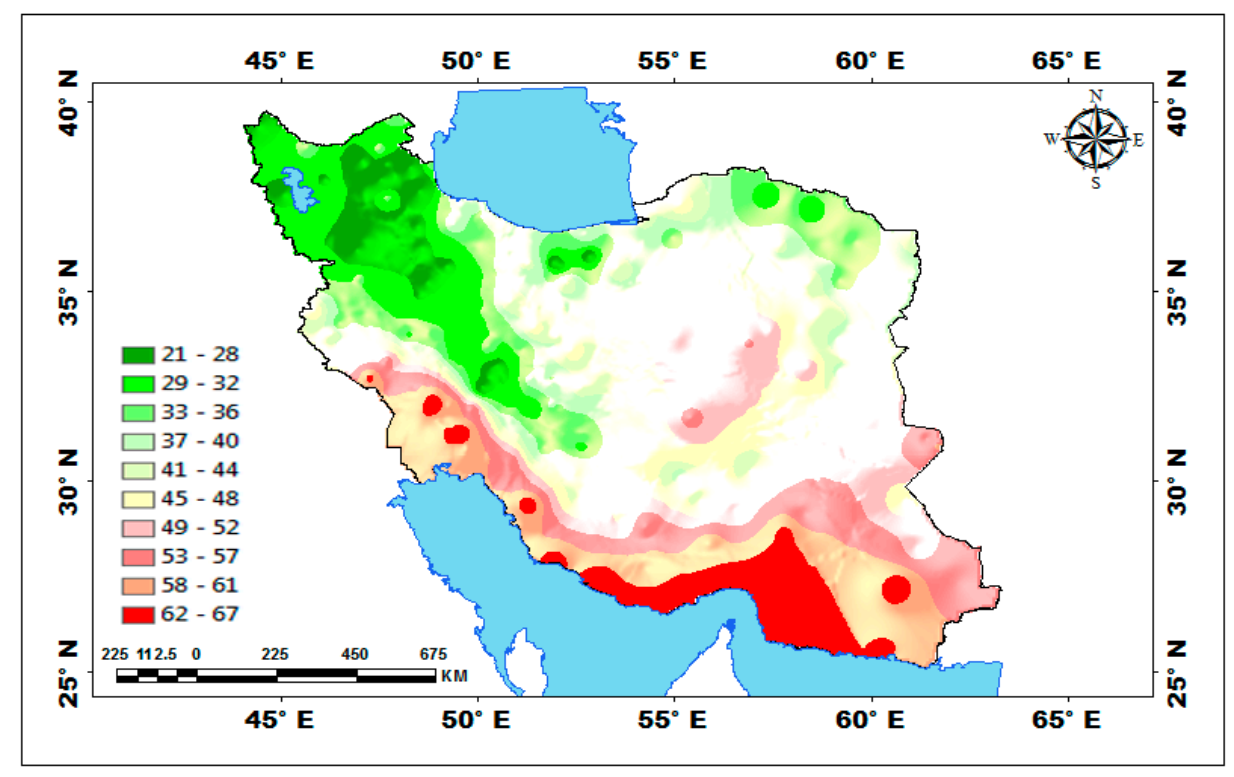

Figure 5. The coefficient of variations of Annual Temperature (\%).

Figure 6 shows the variation patterns of rainfall for all 174 stations as about $3.4 \%-110 \%$ which are decreasing from north to south for the annual period (inverse pattern of temperature). Figure 6 shows the variation patterns of elevation for all 39,055 elevation points in the annual period as about $0 \%-48 \%$ which are irregular in Iran and are increasing in the western mountainous region. Therefore, we evaluated our hypotheses by computing the six models of the effect of temperature and elevation on rainfall. 


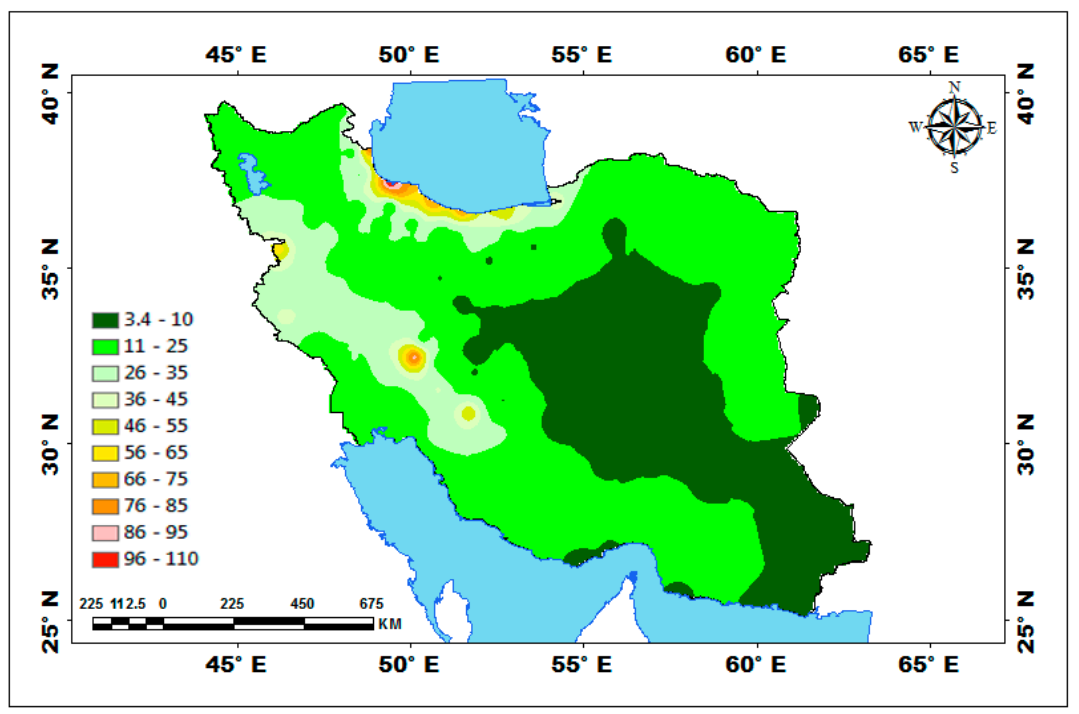

Figure 6. The coefficient of variations of Annual Rainfall (\%).

\subsection{Temporal Correlation Analysis}

Analyzing the elevation distribution according to the height values will produce topological changes, providing the analysis of the effects of topography on rainfall in Iran. Iran's variations of elevation distribution are shown in Figure 2 for different elevation levels by using 39,055 elevations points. For every level, the average elevation between the mean of elevation points' amounts from all levels is presented. According to data properties, we computed a temporal correlation coefficient between the rainfall, temperature, and elevation amounts for all stations. According to Table 3, there are significant correlation coefficients between the temperature, elevation, and rainfall for Iran and for all periods.

Table 3. The significant correlation coefficient.

\begin{tabular}{ccccc}
\hline $\begin{array}{c}\text { Temperature } \\
\text { Variable }\end{array}$ & $\begin{array}{c}\text { Estimate or } \\
\text { (Regression Weights) }\end{array}$ & $\begin{array}{c}\text { Standard Error } \\
\text { (S.E.) }\end{array}$ & $\begin{array}{c}\text { Citical Ratio } \\
\text { (C.R.) }\end{array}$ & $\boldsymbol{P}$ \\
\hline January & 33.569 & 3.617 & 9.282 & $* * *$ \\
February & 18.400 & 1.776 & 10.360 & $* * *$ \\
March & 1.000 & 3.024 & 9.248 & $* * *$ \\
April & 15.467 & 1.491 & 10.376 & $* * *$ \\
May & 27.967 & 3.024 & 9.248 & $* * *$ \\
June & -538.782 & 119.484 & -4.509 & $* * *$ \\
July & 20.416 & 2.207 & 9.249 & $* * *$ \\
August & 843.016 & 121.951 & 6.913 & $* .605$ \\
September & 890.964 & 134.886 & 11.933 & $* * *$ \\
October & 7.076 & 0.593 & 10.376 & $* * *$ \\
November & 1.000 & 1.491 & 9.343 & $* * *$ \\
December & 22.709 & 2.431 & -4.215 & $* * *$ \\
Elevation & $-64,645.096$ & $15,338.641$ & &
\end{tabular}

In Table 3, the test statistics are the Citical Ratio (C.R.), which represents the parameter estimate (regression weights) divided by its Standard Error (S.E.); as such, it operates as a z-statistic in testing that the estimate is statistically different from zero. There are differences in the regression weights of variables between models for all temperatures, topography and rainfall $(* * *<0.001)$. The critical ratio is the significance of path coefficients. When the Critical Ratio (CR) is $>1.96$ for a regression weight, that path is significant at the 0.05 level or higher (that is, its estimated path parameter is significant). In the $p$-value column, three asterisks $(* *)$ indicate significance smaller than 0.001 . 
The results of temporal correlation computation are shown in Table 4 between the temperature, elevation, and rainfall for monthly, seasonal, and annual periods. According to Table 4, there are negative values between the temperature and rainfall for Iran and for all periods, except January and December (with weak correlation). According to Table 4, there are negative values between the elevation and rainfall for Iran and for all periods, except winter and spring and the months of February, March, April, and May (with weak correlation). Table 4 also shows the determination coefficient $\left(R^{2}\right)$ between the rainfall, temperature, and elevation amounts for all stations. According to Table 4, there are no significant determination coefficients between the temperature, elevation, and rainfall for Iran and for all periods, except winter and the month of April (under the 65\%).

Table 4. The results of the correlation analysis between temperature, elevation and rainfall.

\begin{tabular}{cccccc}
\hline Period & $\begin{array}{c}\text { R Temperature } \\
\text { and Rain }\end{array}$ & $\mathbf{R}^{\mathbf{2} \%}$ & $\begin{array}{c}\mathbf{R} \text { Temperature } \\
\text { and Elevation }\end{array}$ & $\mathbf{R}^{\mathbf{2} \%}$ & $\begin{array}{c}\text { R Elevation } \\
\text { and Rain }\end{array}$ \\
\hline Annual & -0.304 & 1.02 & -0.086 & 59.60 & -0.086 \\
Autumn & -0.101 & 3.72 & -0.772 & 55.80 & -0.199 \\
Winter & -0.193 & 63.84 & -0.747 & 43.30 & 0.069 \\
Spring & -0.799 & 4.80 & -0.658 & 41.73 & 0.277 \\
Summer & -0.219 & 0.42 & -0.646 & 61.31 & -0.312 \\
January & 0.065 & 5.06 & -0.783 & 54.91 & -0.094 \\
February & -0.225 & 17.39 & -0.741 & 48.86 & 0.104 \\
March & -0.417 & 57.76 & -0.699 & 46.10 & 0.203 \\
April & -0.760 & 63.84 & -0.679 & 44.49 & 0.73 \\
May & -0.799 & 22.28 & -0.667 & 37.21 & 0.412 \\
June & -0.472 & 14.98 & -0.610 & 33.99 & 0.269 \\
July & -0.387 & 4.45 & -0.583 & 40.96 & -0.183 \\
August & -0.211 & 2.16 & -0.640 & 48.58 & -0.234 \\
September & -0.147 & 2.82 & -0.697 & 56.10 & -0.315 \\
October & -0.168 & 3.13 & -0.749 & 60.37 & -0.322 \\
November & -0.177 & 0.13 & -0.777 & 59.91 & -0.267 \\
December & 0.036 & 1.02 & -0.774 & 59.60 & -0.148 \\
\hline
\end{tabular}

Squared multiple correlation $\left(R^{2}\right)$ is an indicator of the ratio of the variance of the endogenous variable (annual rainfall) that is estimated by temperatures and topography variables. It is assumed that the higher the value of the squared multiple correlation, the greater the explanatory rule of the regression model, and thus the better the prediction of the dependent variable. The squared multiple correlations (the coefficient of determination) show that $0.638 \%$ or $63.8 \%$ of the variance of support for the April temperature is estimated by the variance in April rainfall. The model cannot explain the remaining $0.362 \%$ or $36.2 \%$ of the variance of support for April temperature. However, a significant relation is not observed between temperature, elevation, and rainfall in the entire region. $R^{2}$ was only significant for the season of winter and the month of April in the period 1975-2014 (Table 5). Testing was implemented with Student's $t$ test having degrees of freedom of 173 and a critical value of 1.96 . The significant Student's $t$ test between temperature and precipitation in Iran was only observed by comparing the relation of elevation and rainfall.

In temporal correlation analysis between the monthly temperatures and annual rainfall (Figure 7), we observed a significant negative relationship (with the exception of the months of January, February, March and December), a significant positive relationship $\left(R^{2}=0.86\right)$ with other months, especially with August $\left(Z\right.$ or C.R. $=\frac{\text { Estiamte }}{\text { Standard error }}=\frac{843.016}{121.951}=6.913, P_{\text {value }}=0.000$ for direct relationship $)$ and September $\left(Z\right.$ or C.R. $=\frac{\text { Estiamte }}{\text { Standard error }}=\frac{890.964}{134.886}=6.605, P_{\text {value }}=0.000$ for direct relationship $)$, and conflicting direct effects of monthly temperatures on annual rainfall (Figure 7). According to Figure 7 , there are different relationships $\left(0.0<\mathrm{R}^{2}<0.99\right)$ between the temperature series and annual rainfall in Iran. Also, there were significant relationships $\left(\mathrm{PE}_{\mathrm{sig}}=\frac{\mathrm{X}^{2}}{D F}=\frac{155.76}{55}=2.832\right.$, RMSEA $=0.005$ and $P=0.000$ ) for the first model between the temperature series and annual rainfall (Figure 7). The direct positive relationship of the temperature to annual rainfall (August $=0.47$ and September $=0.44$ ) is an important aspect in Iran compared to other months, 
whereas the direct negative relationship of the temperature to annual rainfall was estimated (June and July $=-0.36)$ as an essential aspect in Iran compared to other months.

Table 5. The main effects of rainfall values for all stations (Temperature and Elevation).

\begin{tabular}{cccccc}
\hline \multirow{2}{*}{ Variable } & \multirow{2}{*}{$\begin{array}{c}\text { Correlation } \\
\text { Coefficient }\end{array}$} & \multicolumn{2}{c}{$\mathbf{9 5 . 0 0 \% \text { Confidence Interval }}$} & \multirow{2}{*}{$\boldsymbol{t}$} & \multirow{2}{*}{$\boldsymbol{p}$-Value } \\
\cline { 3 - 4 } & Lower Limit & Upper Limit & & & \\
\hline Temperature Rainfall & -0.304 & -0.447 & -0.145 & 3.743 & 0.000 \\
Elevation Rainfall & -0.086 & -0.248 & 0.081 & 1.012 & 0.313 \\
\hline
\end{tabular}

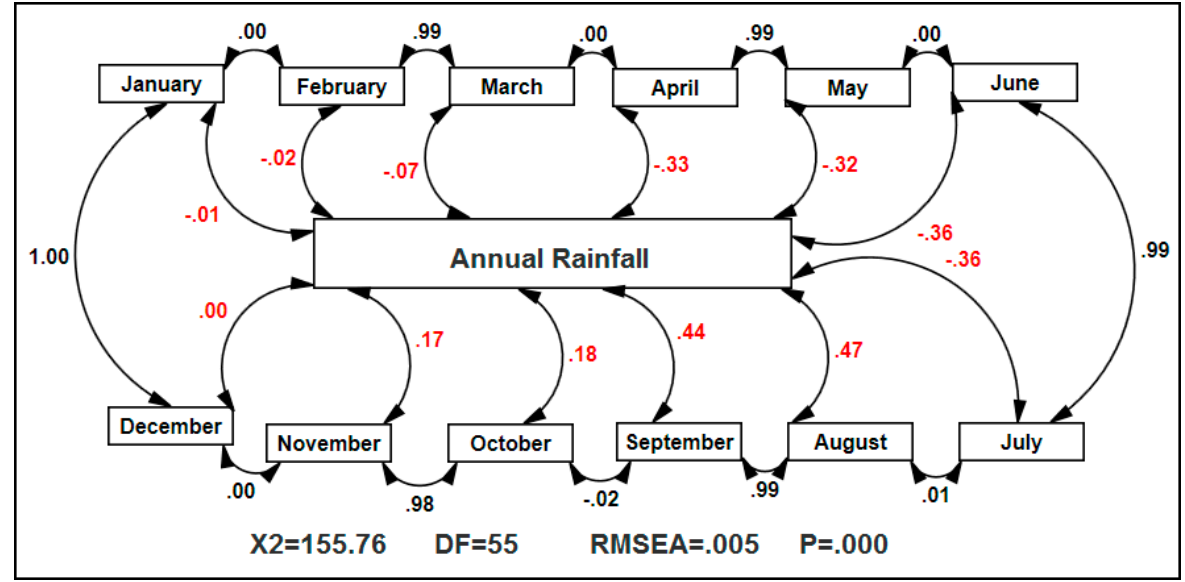

Figure 7. The temporal correlation analysis between the monthly temperatures and annual rainfall. In Figure 7, the double-headed arrows indicate covariance or correlation between pairs of variables. The correlation model shows that monthly temperatures have negative and positive correlations (red data) on annual rainfall. In the model summary presented in Figure 7, we observed the overall chi-square $\left(\chi^{2}\right)$ value, together with its degrees of freedom, RMSEA 0.005 (a suitable fit) and probability value.

Principally, the degrees of monthly temperature effectiveness on annual rainfall differed significantly in Iran. In a temporal correlation analysis between the elevation, monthly temperature and annual rainfall (Figure 8$)$, a significant negative correlation $\left(N E_{s i g}=\frac{X^{2}}{D F}=\frac{156.56}{61}=2.57\right.$, RMSEA $=0.008$ and $P=0.000)$ between elevation and annual rainfall $(R=-0.30)$ and conflicting direct effects of monthly temperature on annual rainfall were observed (Figure 8).

\subsection{Spatial Correlation Analysis}

We computed spatial correlations between the rainfall, temperature, and elevation amounts for all stations. Spatial correlations between the rainfall, temperature, elevation and DEM weres measured by analyzing the experimental cross-variograms. A curve such as that in the cross-variogram was described by Nugget Variance or $C_{0}$ (the y-intercept of the model); Sill or $C_{0}+C$ (the model asymptote; and Range or A (the separation distance over which spatial dependence is supposed). Such a curve can be modeled by using three parameters-a nugget variance, a sill, and a range. The Residual Sums of Squares (RSS) presents a careful measure of how well the model fits the variogram data; the lower the reduced sums of $s$ are, the better the model fits. The $\mathrm{r}^{2}$ shows a signal of how well the model fits the variogram data; this value is not as sensitive or robust as the RSS value for best-fit calculations; use RSS to judge the effect of changes in model parameters. Ratio $C /\left(C_{0}+C\right)(R N S)$, a kind of statistics, presents a measure of the ratio of sample variance $\left(C_{0}+C\right)$ that is illuminated by spatially structured variance $C$. This value will be 1.0 for a variogram with no nugget variance; conversely, it will be 0 where there is no spatially dependent variation at the range indicated, i.e., where there is a theoretical nugget 
effect. In spatial correlation analysis, there are two models; the isotropic (straight line variogram) and Anisotropic variograms (directional information in the range parameter). In this study, we applied the Anisotropic variograms by a linear model (each model can be depicted using the terms Nugget Variance or $C_{0}$; Sill or $C_{0}+C$; Range or $A(A 1$-the range parameter for the major axis of variation and $A 2$-the range parameter for the minor axis); Ratio $C /\left(C_{0}+C\right)$ or RNS and RSS. The cross-variograms depicted between the rainfall, temperature, elevation and DEM are displayed in Figure 9. The type of correlation is displayed by the distributed lines in Figure 9.

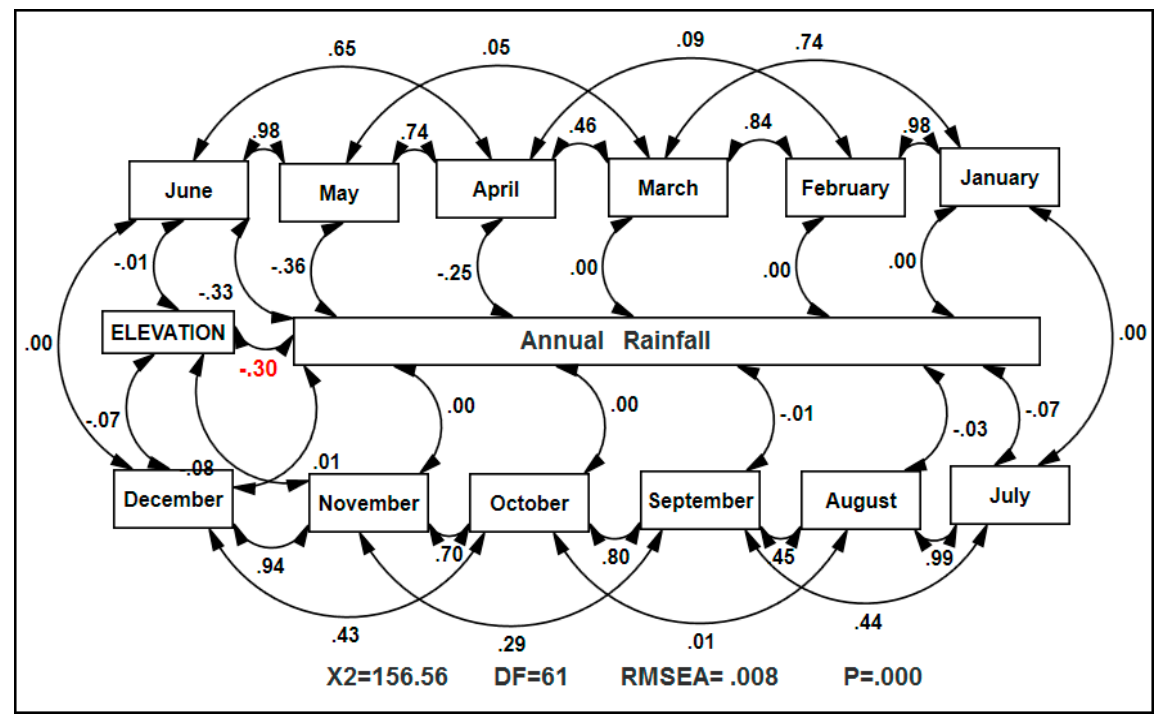

Figure 8. The correlation between the monthly temperatures, elevation and annual rainfall. Figure 8 also shows the temporal correlation coefficients between the temperatures, rainfall and elevation amounts for all stations.

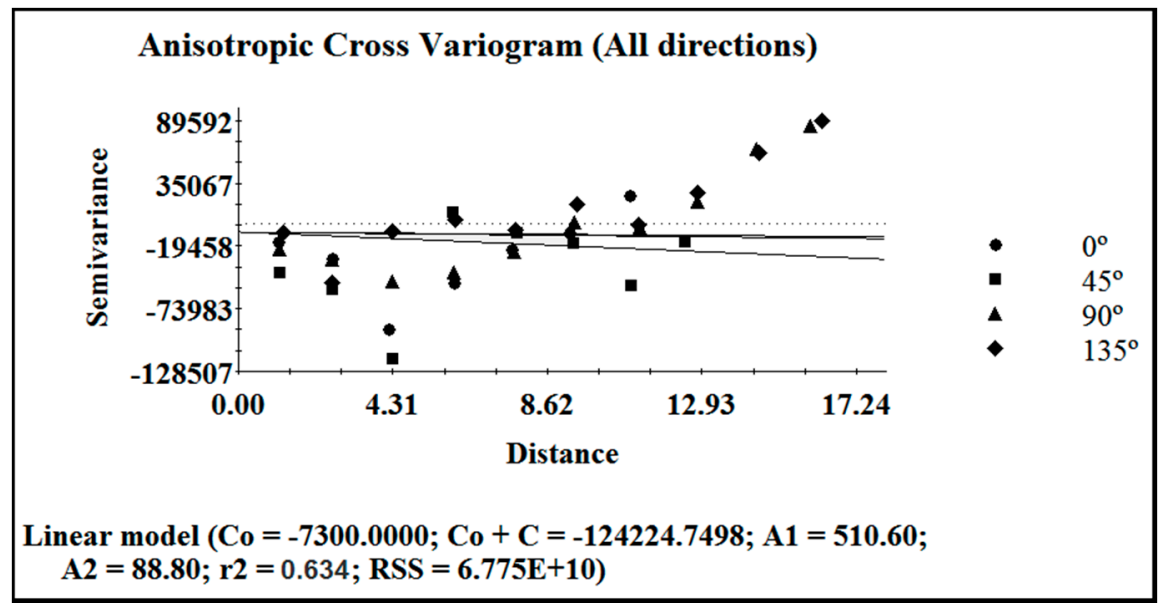

Figure 9. Spatial correlation between the elevation and rainfall. Linear cross-variograms (dots) and measured spherical models (solid lines). The dashed lines show that there is a positive relationship between observed variables. Variogram factors: nugget variance or $C_{0}$; Sill or $C_{0}+C$; Range or $A$ ( $A 1$ - the range parameter for the major axis of variation and $A 2$-the range parameter for the minor axis); Ratio $C /\left(C_{0}+C\right)$ or RNS and RSS. The linear anisotropic model describes a straight-line variogram $\left(\gamma(h)=C_{0}+\mathrm{h}\left(\frac{C}{A}\right)\right.$ that $\gamma(h)=$ semi variance for interval distance class $h, h=$ lag interval, $C_{0}=$ nugget variance $\geq 0, C=$ structural variance $\geq C_{0}=\sqrt{\left\{A_{1}^{2}\left[\cos ^{2}(\theta-\Phi)\right]\right\}}+\left\{A_{2}^{2}\left[\sin ^{2}(\theta-\Phi)\right]\right\}$, $A 1=$ range parameter for the major axis $(\Phi)$ and $A 2=$ range parameter for the minor axis $(\Phi+90)$. 
The cross-variograms between the rainfall, temperature, elevation and DEM displayed both negative and positive effects for lag distances, revealing that variables vary in different methods with the lag distance. As stated by Rosemary et al. (2017), the rainfall, temperature, elevation and DEM values displayed strong spatial dependencies (RNS $<25 \%$ ) (Figure 10), while all the other series revealed a moderate spatial dependency $(25 \%<\mathrm{RNS}<75 \%)$; all the other series showed a moderate spatial irregularity $(75 \%<$ RNS $<100 \%)$; and all the other series showed a strong spatial irregularity (RNS $>100 \%$ ) [33] (Figure 11).

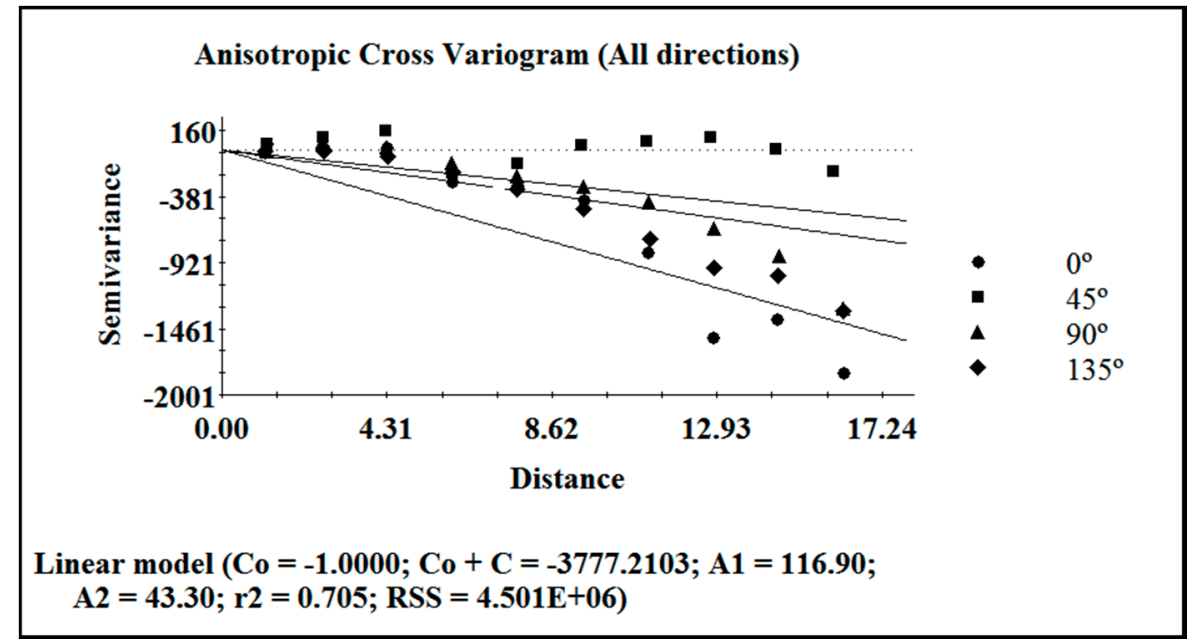

Figure 10. Spatial correlation between the Temperature and Rainfall.

According to the cross-variograms, the elevation and rainfall revealed a strong spatial irregularity (RNS > 105.87\%) between the elevation and rainfall (Figure 10). In addition, the cross-variograms, the temperature and rainfall showed a strong spatial irregularity (RNS $>100.01 \%$ ) (Figure 10), whereas the cross-variograms, the DEM, and rainfall (RNS $=99.98 \%$ ) displayed a moderate spatial irregularity $(75 \%<$ RNS $<100 \%$ ) (Figure 11). The change of variograms suggested the presence of spatial irregularity (significant spatial non-dependence) for rainfall, temperature, elevation and DEM over a distance which displayed that the extreme amount of spatial irregularity is presented by natural variability of rainfall patterns. We analyzed the correlogram between the rainfall, temperature, DEM and elevation amounts for all stations.

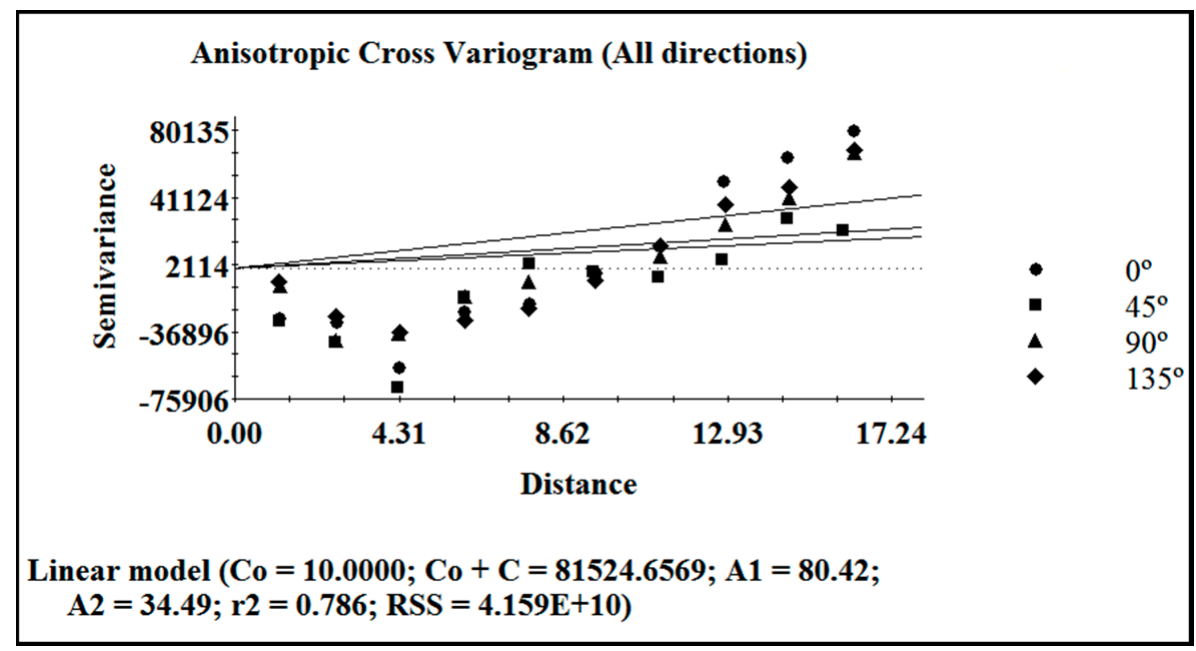

Figure 11. Spatial correlation between the DEM and Rainfall. 
The correlogram is the most commonly used statistics for autocorrelation analyses in climatic studies. These are the essential statistics for predicting the spatial pattern analysis by Moran's I statistic. A way of assessing the correlation coefficient in the existence of autocorrelation is to use the amount of degrees of freedom - a method established by Clifford et al. (1989) [73]. The correlograms depicted between the rainfall, temperature, elevation and DEM are displayed in Figures 9-11. According to Figures 9-11, the sampling interval between the temperature, elevation, DEM, and rainfall for predicting the spatial pattern analysis using autocorrelation analyses difference was suggested. Distance testing was applied as a sampling interval for the spatial correlation between the temperature and rainfall and the amount of rainfall. It was estimated to be less than $7.5 \mathrm{~m}$ in Iran, while the sampling interval for the spatial correlation between the elevation and rainfall was calculated and the amount of rainfall was estimated to be less than $3.1 \mathrm{~m}$; the sampling interval for the spatial correlation between DEM and rainfall was estimated to be less than $3.4 \mathrm{~m}$. However, the rainfall, temperature, elevation and DEM changes are measured spatially correlated, and the temperature, is showed the more variations spatially.

\subsection{Effectiveness Analysis}

The effectiveness between monthly, seasonal and annual temperatures, elevation and DEM on rainfall for the regionalization of rainfall by using causal models has also been analyzed. According to Figure 12, there is significant positive effectiveness ( $\left.\mathrm{PE}_{\text {sig }}\right)$ between February, May, August and December temperature and annual rainfall in Iran, while the significant negative effectiveness between March, April and September temperatures and annual rainfall was observed (Figure 12). It suggests that the maximum effectiveness of the positive temperature to annual rainfall (February $=1.16$ ) and maximum effectiveness of the negative temperature to annual rainfall (March $=-1.46$ ) is an important aspect compared to other months in Iran.

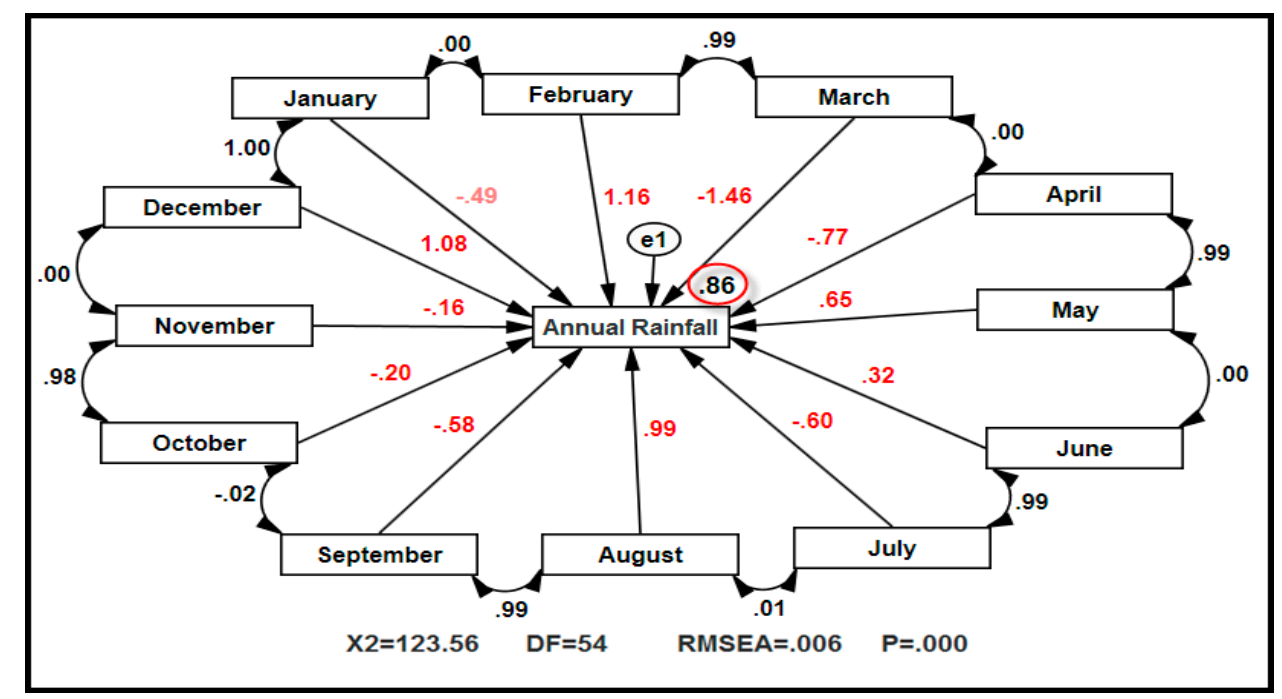

Figure 12. The effectiveness analysis between the monthly temperatures and annual rainfall. Effectiveness model analyzed casually in each climatic series. The single-headed arrows denote causal relationships and the impact of one variable on another; the double-headed arrows indicate covariance or correlation between pairs of variables. The SEM model shows that monthly temperatures have a direct effect (red data) on annual rainfall. Monthly temperatures have direct effects (positive and negative) on annual rainfall and monthly temperatures have a correlation with neighborhood series. An error term (e1) is associated with an observed variable (annual rainfall). In the model summary presented in Figure 12, the overall chi-square $\left(\chi^{2}\right)$ value, together with its degrees of freedom and probability value was observed. 
A significant direct positive effectiveness $\left(0.80<R^{2}<1\right)$ between monthly temperature and annual rainfall, especially with February, was investigated $\left(Z\right.$ or $C . R .=\frac{\text { Estiamte }}{\text { Standard error }}=\frac{\mathbf{1 1 5 . 2 3 7}}{\mathbf{2 . 9 9}}=38.545$, $P_{\text {value }}=0.000$ for indirect effect ) (0.46). Differing indirect effects (in the first model) of monthly temperatures on annual rainfall $\left(\mathrm{PE}_{\mathrm{sig}}=\frac{X^{2}}{D F}=\frac{161.23}{59}=2.73\right.$, RMSEA $=0.006$ and $\left.P=0.000\right)$ (Figure 13). Moreover, there was a significant indirect positive effectiveness $\left(0.80<R^{2}<1\right)$ between monthly temperature and annual rainfall, especially in May (Indirect $=2$ ) and a significant indirect negative effectiveness between monthly temperature series, especially in June (indirect $=-1.09$ ).

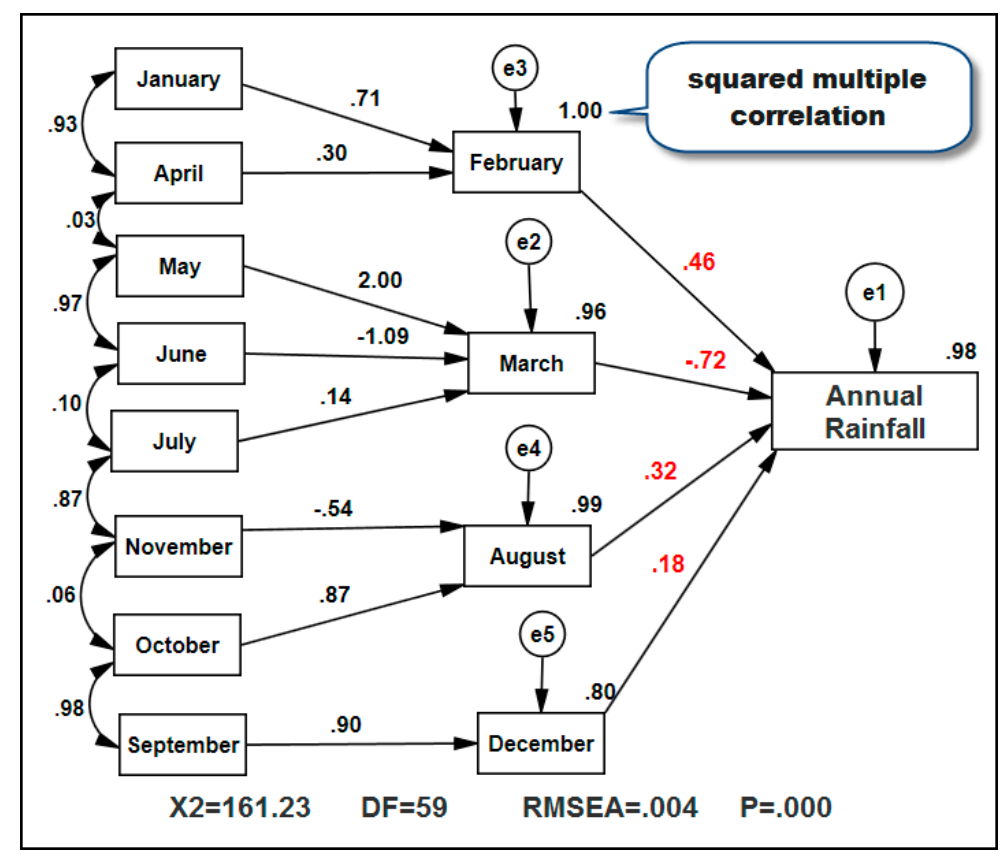

Figure 13. The effectiveness between the monthly temperatures and annual rainfall (first model). Monthly effectiveness investigated casually in rainfall series. The effectiveness model shows that eight monthly temperature series (January, April, May, June, July, October, November and September based on Standardized $\beta$ higher) have an indirect effect on annual rainfall. Monthly temperature series (February, March, August and December) have direct effects (positive and negative) on annual rainfall.

According to Figure 14, there is significant positive $\left(0.94<R^{2}<1\right)$ effectiveness between the temperature series and annual rainfall in Iran. In addition, the significant positive effectiveness $\left(\mathrm{PE}_{\mathrm{sig}}=\frac{X^{2}}{D F}=\frac{173.65}{58}=2.99, R M S E A=0.006\right.$ and $\left.P=0.000\right)$ was observed for the second model between the temperature series and annual rainfall (Figure 14).

According to Figure 15, there is significant positive $\left(0.99<R^{2}<1\right)$ effectiveness between the temperature series and annual rainfall in Iran. Moreover, the significant positive effectiveness $\left(\mathrm{PE}_{\mathrm{sig}}=\frac{X^{2}}{D F}=\frac{\mathbf{1 2 1 . 3 4 6}}{48}=2.52, \mathrm{RMSEA}=0.007\right.$ and $\left.P=0.000\right)$ for the third model was observed between the temperature series and annual rainfall (Figure 15) and the maximum indirect effectiveness of the temperature to annual rainfall (May $=0.89$ and November $=0.72$ ) compared with other months in Iran.

According to Figure 16, there is significant positive and negative $\left(0.86<R^{2}<0.99\right)$ effectiveness between the temperature series and annual rainfall in Iran. Also, the significant positive effectiveness $\left(\mathrm{PE}_{\mathrm{sig}}=\frac{X^{2}}{D F}=\frac{48.342}{23}=2.102, R M S E A=0.003\right.$ and $\left.P=0.000\right)$ for the fourth model was observed between the temperature series and annual rainfall (Figure 16), the maximum indirect positive effectiveness of the temperature to annual rainfall (May $=3.1$ and October $=1.31$ ) and also the maximum indirect negative effectiveness of the temperature to annual rainfall (June $=-2.39$ ) as an important characteristic compared to other months in Iran. 


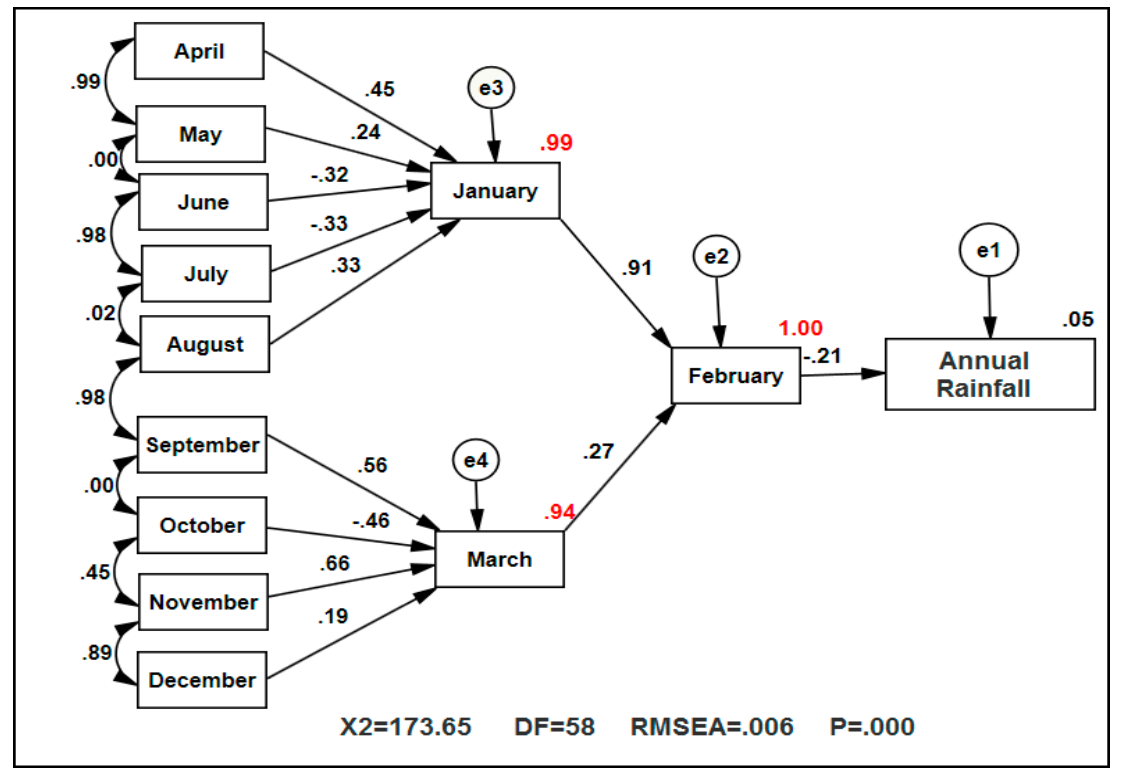

Figure 14. The effectiveness between the monthly temperature and annual rainfall (second model). Monthly effectiveness investigated on annual rainfall series. The effectiveness model shows that nine monthly temperature series (January, March, April, May, June, July, August, September, October, November and December) have indirect effects on annual rainfall. February temperature has a direct effect (negative effect) on annual rainfall. According to Figure 14 , there is significant $\left(0.94<R^{2}<1\right)$ effectiveness (red data) between the temperature series and annual rainfall in Iran.

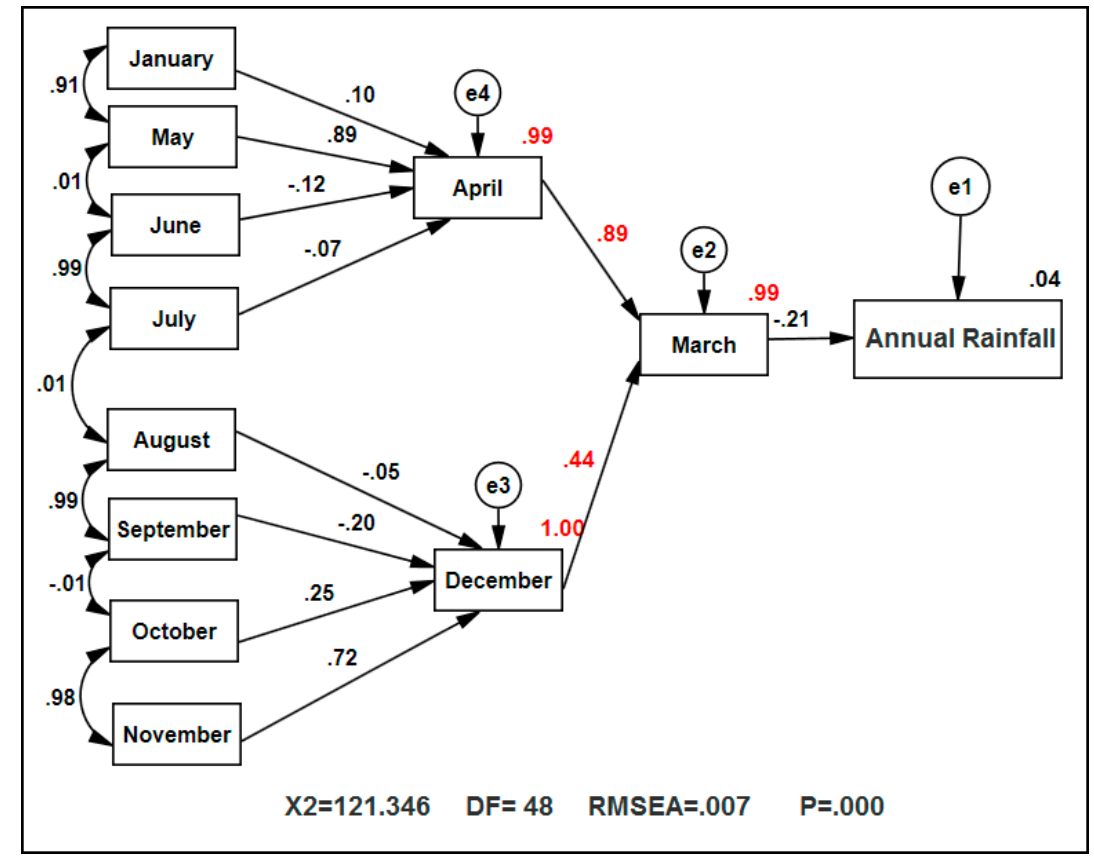

Figure 15. The effectiveness between the monthly temperature and annual rainfall (third model). Monthly effectiveness investigated on annual rainfall series. The effectiveness model shows that ten monthly temperature series (January, April, May, June, July, August, September, October, November and December) have an indirect effect on annual rainfall. March temperature has a direct effect (negative effect) on annual rainfall. 


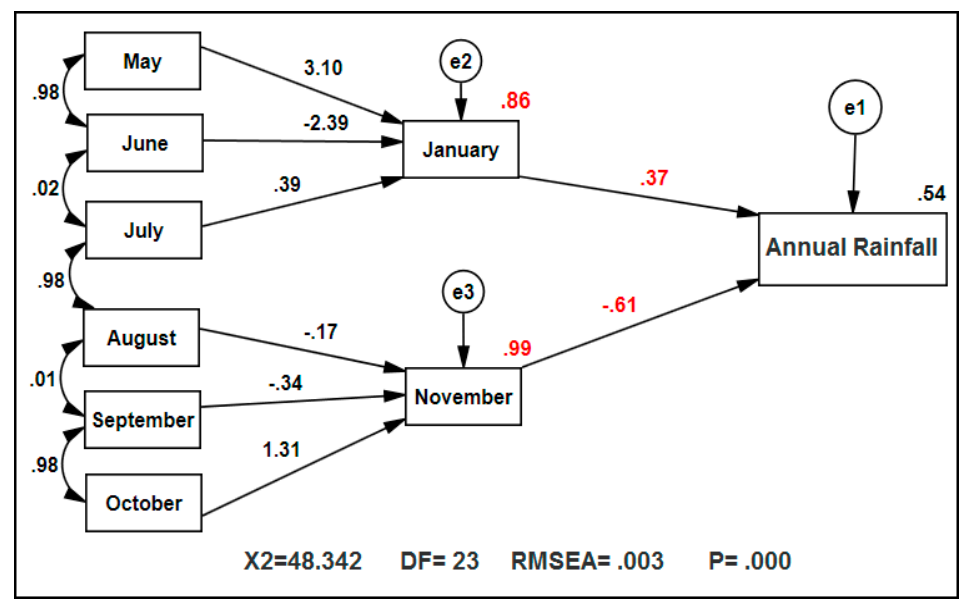

Figure 16. The effectiveness between the monthly temperature and annual rainfall (fourth model). Monthly effectiveness investigated on annual rainfall series. The effectiveness model shows that eight monthly temperature series (May, June, July, August, September, October, November and December) have indirect effects on annual rainfall. January and November temperature series have a direct effect (negative and positive effects) on annual rainfall $\left(0.86<\mathrm{R}^{2}<0.99\right.$, red data).

According to Figure 17, there is significant positive and negative $\left(R^{2}=0.99\right)$ effectiveness between the temperature series and annual rainfall in Iran. In addition, the significant positive effectiveness $\left(\mathrm{PE}_{\mathrm{sig}}=\frac{\mathrm{X}^{2}}{D F}=\frac{18.623}{8}=2.33, \mathrm{RMSEA}=0.006\right.$ and $\left.P=0.000\right)$ for the fifth model was observed between the temperature series and annual rainfall (Figure 17) and the maximum indirect effectiveness of the temperature to annual rainfall (September $=1.29$ ) as an essential property compared to other months in Iran.

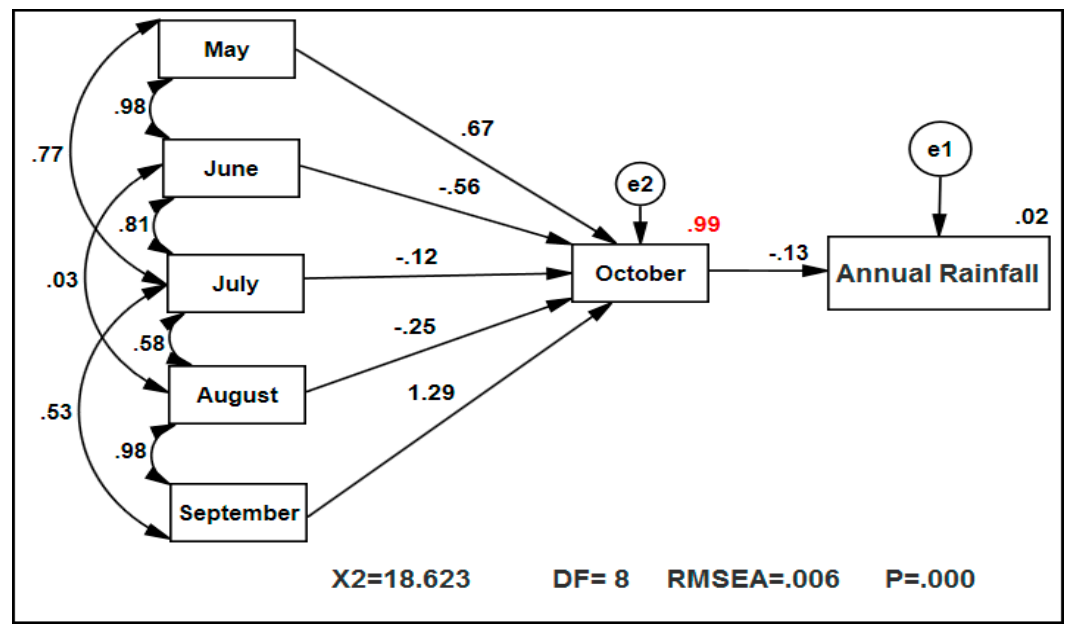

Figure 17. The effectiveness between the monthly temperature and annual rainfall (fifth model). Monthly effectiveness investigated on annual rainfall series. The effectiveness model shows that six monthly temperature series (May, June, July, August and September) have an indirect effect on annual rainfall. October temperature has a direct effect (negative effect) on annual rainfall $\left(R^{2}=0.99\right.$ or $99 \%$, red data).

According to Figure 18 , there is weak negative effectiveness $\left(\mathrm{NE}_{\text {sig }}\right)$ between the elevation and monthly temperature and annual rainfall in Iran (sixth model), while the significant negative effectiveness between the March and February temperature (1.23 and -2.02) and annual rainfall was observed (Figure 18). This indicates the maximum indirect effectiveness of the positive temperature to 
annual rainfall (May $=1.52$ ) and the maximum indirect effectiveness of the negative temperature to annual rainfall (June $=-0.72$ ) as a valuable property evaluated against other factors in Iran.

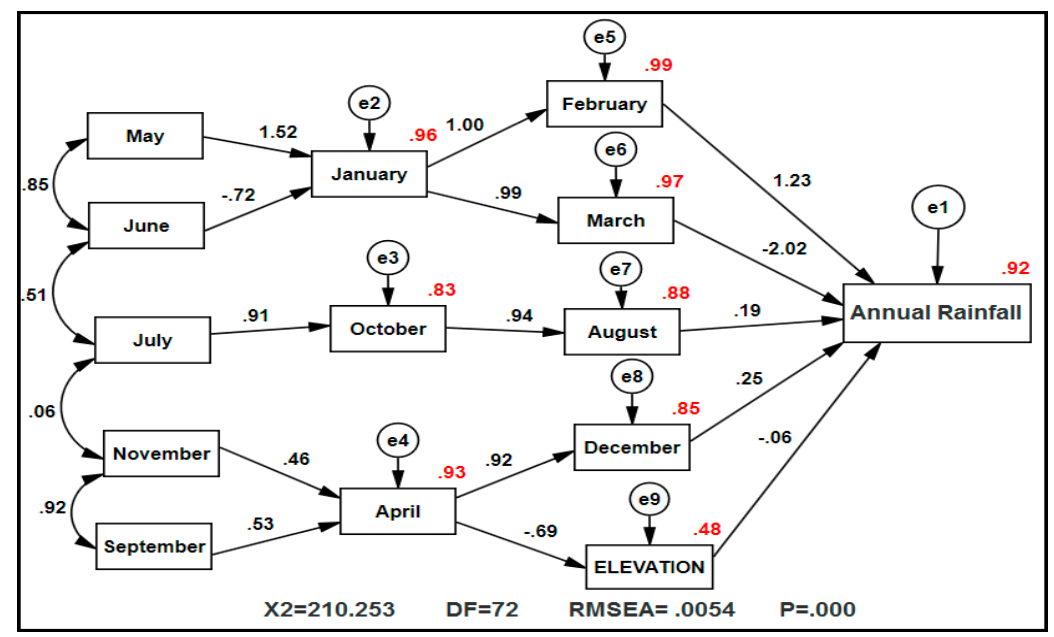

Figure 18. The effectiveness of the temperatures and elevation on annual rainfall (sixth model). Monthly effectiveness investigated on annual rainfall series. The effectiveness model shows that eight monthly temperature series (January, April, May, June, July, September, October and November) have indirect effects on annual rainfall. February, March, August, December temperatures and elevation have direct effects (negative and positive effects) on annual rainfall $\left(0.48<\mathrm{R}^{2}<0.99\right.$, red data).

According to Figure 19, there is weak negative effectiveness $\left(\mathrm{NE}_{\text {sig }}\right)$ between the elevation, DEM, monthly temperature and annual rainfall in Iran. Moreover, the significant negative effectiveness was observed between the DEM $\left(R^{2}=0.66\right)$, elevation $\left(R^{2}=0.48\right)$, monthly temperature $\left(0.83<R^{2}<0.99\right)$ and annual rainfall (Figure 19). This indicates the weak direct effectiveness of DEM $(-0.02)$ and elevation $(-0.05)$ to annual rainfall as an important property evaluated against rainfall formation factors (seventh model) in Iran.

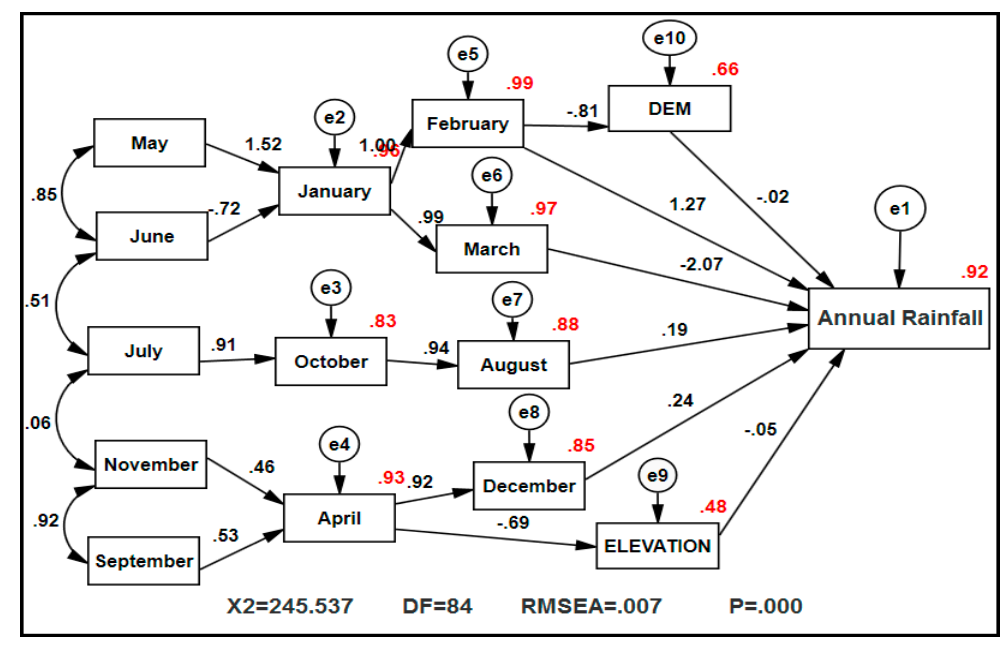

Figure 19. The effectiveness of the temperatures, elevation, and DEM on annual rainfall (seventh model). Monthly effectiveness investigated on annual rainfall series. The effectiveness model shows that eight monthly temperature series (January, April, May, June, July, September, October and November) have indirect effects on annual rainfall. February, March, August, December temperature series, elevation and DEM have direct effects (negative and positive effects) on annual rainfall $\left(0.48<\mathrm{R}^{2}<0.99\right.$, red data). 
The effectiveness of seasonal temperature, elevation and DEM on the annual rainfall was computed. According to Figure 20, there is strong direct positive effectiveness $\left(\mathrm{PE}_{\text {sig }}\right)$ between the autumn temperature and annual rainfall in Iran. However, the significant positive effectiveness between the autumn temperature $\left(R^{2}=0.63\right)$ and annual rainfall was observed (Figure 20).

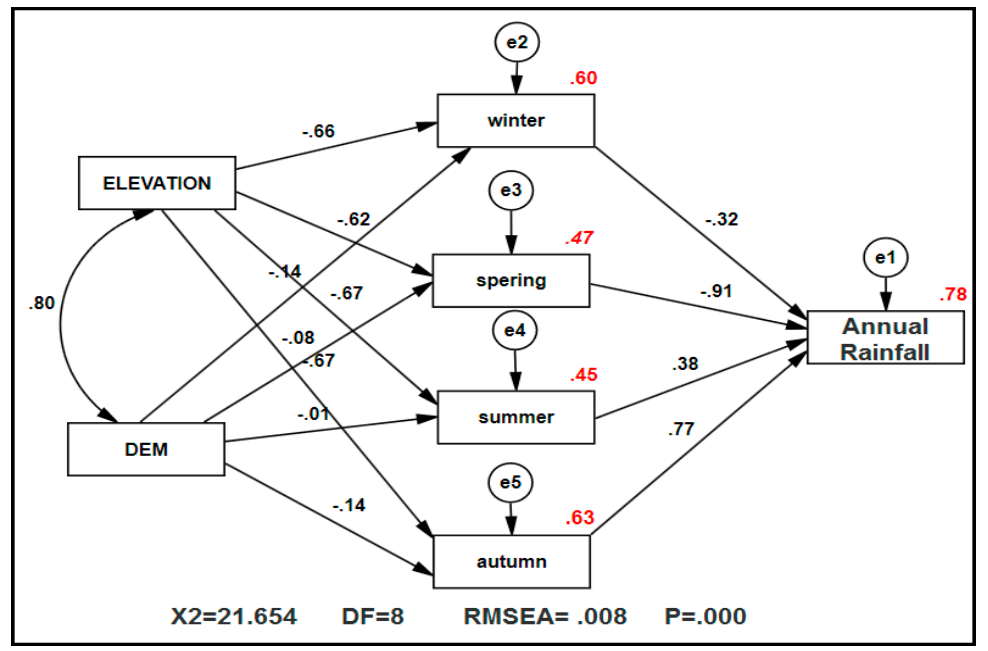

Figure 20. The effectiveness of the seasonal temperatures, elevation, and DEM on annual rainfall (eighth model). Seasonal effectiveness investigated on annual rainfall series. The effectiveness model shows that seasonal temperature series (winter, spring, summer and autumn) have direct effects on annual rainfall. Elevation and DEM have indirect effects (negative and positive effects) on annual rainfall $\left(0.45<\mathrm{R}^{2}<0.60\right.$, red data).

According to Figure 20, there is strong direct negative effectiveness $\left(\mathrm{NE}_{\mathrm{sig}}\right)$ between the spring temperature and annual rainfall in Iran. Significant negative effectiveness was observed between the spring temperature $\left(R^{2}=0.47\right)$ and annual rainfall (Figure 20$)$. In addition, there is weak direct negative effectiveness $\left(\mathrm{PE}_{\text {sig }}\right)$ between the winter temperature $(-0.32)$ and annual rainfall in Iran, while we observed the weak positive effectiveness between the summer temperature (0.38) and annual rainfall (Figure 20). According to Figure 20, there is strong positive effectiveness $\left(\mathrm{PE}_{\text {sig }}\right)$ between the autumn temperature (0.77) and annual rainfall in Iran (eighth model). According to Figure 20, there is strong indirect negative $(-0.67)$ effectiveness $\left(\mathrm{PE}_{\mathrm{sig}}\right)$ between the spring temperature, elevation and DEM and annual rainfall in Iran (eighth model). In addition, effectiveness models in SEM include the measurement model and the structural model. A measurement model measures the latent variables, whereas the structural model investigates all the path pattern relations [74]. However, the analyzed patterns of temperature elevation and DEM effectiveness to annual rainfall (SEM models) are displayed as the effectiveness final model in Figure 21. According to Figure 21, there is strong direct negative effectiveness $\left(\mathrm{NE}_{\mathrm{sig}}\right)$ between the monthly temperature $(-0.66)$ and annual rainfall in Iran (ninth model) and significant negative effectiveness was observed between the topography (elevation and DEM) $\left(R^{2}=0.68\right.$ and 0.92) and annual rainfall (Figure 21). In addition, there is weak direct positive effectiveness $\left(\mathrm{PE}_{\mathrm{sig}}\right)$ between the seasonal temperature $(0.03)$ and annual rainfall in Iran. As it was observed, there was weak positive effectiveness between the summer temperature $(0.96)$ and annual rainfall (Figure 21). Finally, findings of effectiveness between the monthly temperature, seasonal temperature and topography (Figure 21) showed the strong negative effectiveness between the monthly temperature $(-0.66)$, topography $(-0.60)$, and annual rainfall in comparison with seasonal temperature. However, the results of this study suggested that the estimated values of component effectiveness to rainfall varied significantly in Iran. 


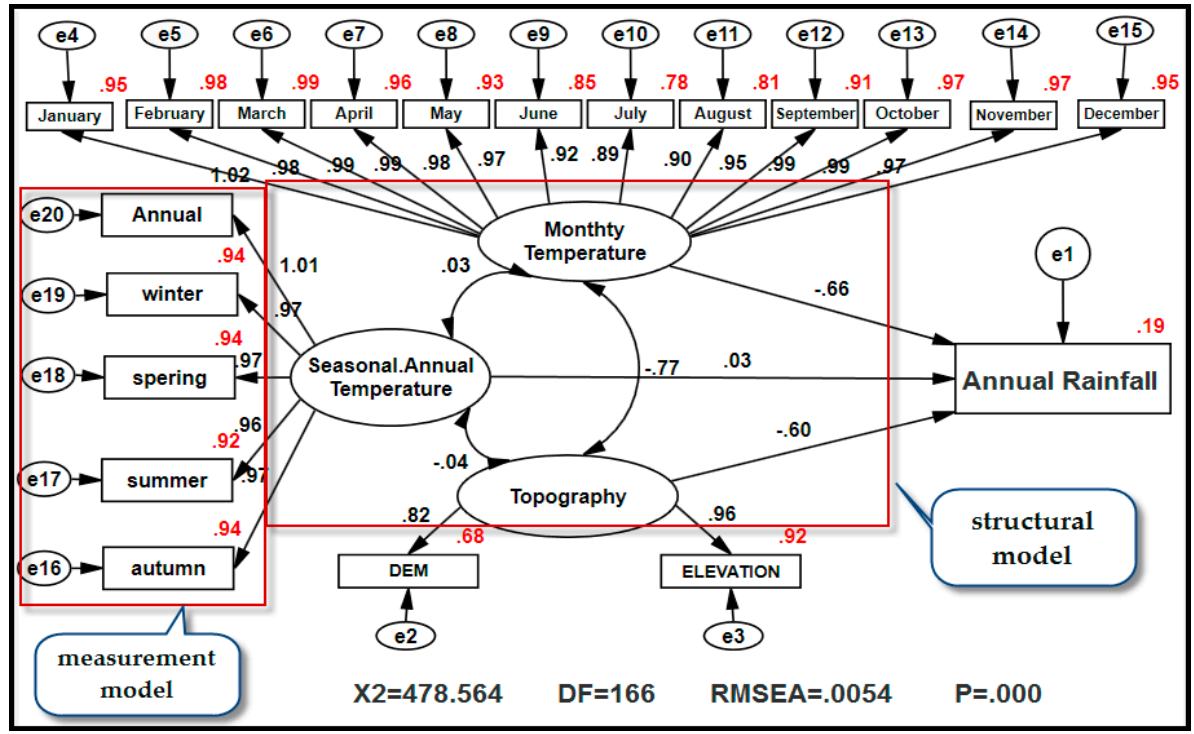

Figure 21. The effectiveness of the temperatures, elevation, and DEM on annual rainfall (final model). Measurement and structural models analyzed on annual rainfall series. The effectiveness and causality model shows that latent variables or factors (monthly temperature series, seasonal and annual temperature series and topography) have direct (negative effects) and indirect effects (negative and positive effects) on annual rainfall $\left(0.68<\mathrm{R}^{2}<0.99\right.$, or $68 \%-99 \%$, red data).

Moreover, mean effect size between the rainfall, temperature, DEM, and elevation amounts for all stations was computed. The main effect plot is most useful for the rainfall, temperature, and elevation amounts for all stations. Main effect plots were used to assess two-way interactions and evaluated the lines to understand how interactions affect the response. Figure 21 shows the main effect plots of rainfall values for all stations, temperature, DEM and elevation for all periods. However, Figure 21 shows that the variables have the main effect. In addition, by comparing the effectiveness of the variables, we can compare the relative magnitude of the effects. Therefore, Figure 21 shows the different effectiveness of temperature, DEM and elevation factors on the rainfall; the negative effects of monthly temperature $(-0.66)$ and topography $(-0.60)$ on rainfall are significant; and the weak positive effect of seasonal and annual temperature (0.03) on rainfall is not significant. Figure 21 also shows that all effects are significant $\left(0.68<R^{2}<0.99\right)$. To determine if a pattern is statistically significant, check the p-value of the term in the analysis of variance in Table 6.

Table 6. Significant effectiveness of factors on annual rainfall.

\begin{tabular}{|c|c|c|c|c|c|c|}
\hline \multicolumn{3}{|c|}{ Effectiveness of Factors } & \multirow{2}{*}{$\begin{array}{c}\text { Estimate } \\
-33.612\end{array}$} & \multirow{2}{*}{$\begin{array}{c}\text { S.E. } \\
6.172\end{array}$} & \multirow{2}{*}{$\begin{array}{l}\text { C.R. } \\
-5.446\end{array}$} & \multirow{2}{*}{$\begin{array}{c}\mathbf{P} \\
000\end{array}$} \\
\hline Annual Rainfall & $<-$ & Monthly_Temperature & & & & \\
\hline Annual Rainfall & $<-$ & Seasonal and Annual Temperature & 1.591 & 1.154 & 1.379 & 0.168 \\
\hline Annual Rainfall & $<-$ & Topography & -0.274 & 0.059 & -4.642 & 000 \\
\hline
\end{tabular}

\subsection{Goodness-of-Fit Indexes of Effectiveness}

The goodness-of-fit index is a widely used and useful index for the evaluation of effectiveness results. In this study, the goodness-of-fit index indicated only effectiveness differences between data series, while the spatially combined valuation indicated noticeable changes in the rainfall on the different scales. The goodness-of-fit index of effectiveness ninth model is presented in Table 7. The goodness-of-fit index was used in this study (Table 7). Table 7 demonstrates that four of the indices of goodness for the sixth models, i.e., CFI 0.991, IFI 0.989, NFI 0.990, and TLI 0.971, are acceptable. 
Based on these findings, it can be claimed that this construct fits the complete model very well. Results indicated that there are factors affecting rainfall in Iran. The findings of this study also indicated that among the three temperature, elevation, and DEM factors ("complete" final model) which were influential in rainfall, the temperature had the highest effect on the rate of rainfall. The hypothesis that the temperature affects the rate of rainfall in Iran is also accepted.

Table 7. Goodness-of-fit indexes of effectiveness final model in Iran.

\begin{tabular}{cccccccccc}
\hline Index & RMR & GFI & AGFI & TLI & IFI & PNFI & PGFI & AIC & CACI \\
\hline Final model & 0.023 & 0.998 & 0.976 & 0.971 & 0.989 & 0.228 & 0.189 & 286.5 & 224.7 \\
\hline Index & NFI & RFI & CFI & PCFI & ECVI & BIC & NCP & FMIN & MECVI \\
\hline Final model & 0.990 & 0.958 & 0.991 & 0.228 & 0.01 & 234.7 & 28.5 & 0.01 & 0.01 \\
\hline
\end{tabular}

\subsection{Regression Analysis}

The effect of temperature, elevation and DEM on rainfall was analyzed by measuring Regression Models (RM). The spatial and temporal regression models were used to explore the effectiveness of the temperature, DEM and elevation amounts on rainfall using spatial and temporal multi-regression models for all stations. For spatial modelling of variables' effectiveness on rainfall, the multi-regression, Ordinary Least Squares (OLS) regression, and Geographically Weighted Regression (GWR) models were applied.

\subsubsection{Temporal Regression Analysis}

A multi-regression model with weights applied to the effect analysis of temperature, DEM and elevation on rainfall was computed. Temperature, DEM, elevation on rainfall, the inequality between the temperature and elevation values and the estimated rainfall value were assessed based on the errors by using linear multi-regression. In linear multi-regression, the estimated relation is calculated by determining the equation that minimizes the sum of the squared distances between the temperature and elevation points and the estimated rainfall values. Equation (19) examines the relationship between temperature (monthly, seasonal and annual) and rainfall with a determination correlation (R-squared) of about $63.89 \%$. In order to analyze the temperature effects on rainfall, the forecasted regression model needs to be used and the following equation is used:

$$
\begin{gathered}
\text { Rainfall }=594-\text { 35.1JAN.Tem }- \text { 62.6FEB.Tem }- \text { 185.2MAR.Tem }- \text { 207.6APR.Tem }+ \\
\text { 17.9MAY.Tem }- \text { 4.4JUNE.Tem }- \text { 40.8JULY.Tem }- \text { 127.0AUG.Tem }- \text { 21.2SEP.Tem }- \\
\text { 81.6OCT.Tem }- \text { 26.4NOV.Tem }- \text { 5.5DEC.Tem + 786ANNUAL }
\end{gathered}
$$

where, Tem is the temperature, JAN is the January month, FEB is the February month, MAR is the March month, and ANNUAL is the annual temperature. The estimated $R$-squared value indicates how well each calculated model predicts the response and is only calculated when cross-validation is used. In this study, the PLS model is selected with the highest estimated $R$. Examining $R$ and estimating $R$-values is done to determine if the model selected by cross-validation is the most appropriate. The estimated $R$-squared between the temperature variables and the estimated rainfall value was measured by using Minitab software with a determination coefficient of about $53.19 \%$. A linear model with weights to forecast the rainfall variations was computed. Figure 22 also shows the annual rainfall spatial pattern variations with a range of about $711 \mathrm{~mm}$ in Iran.

We also forecasted a spatial regression equation by using Equation 19 to analyze the rainfall spatial pattern variations with a range of about $1026 \mathrm{~mm}$ in Iran (Figure 23). The results obtained for Equation 19 statistics for rainfall in any particular month, season, and annual period are presented in Figure 23. 


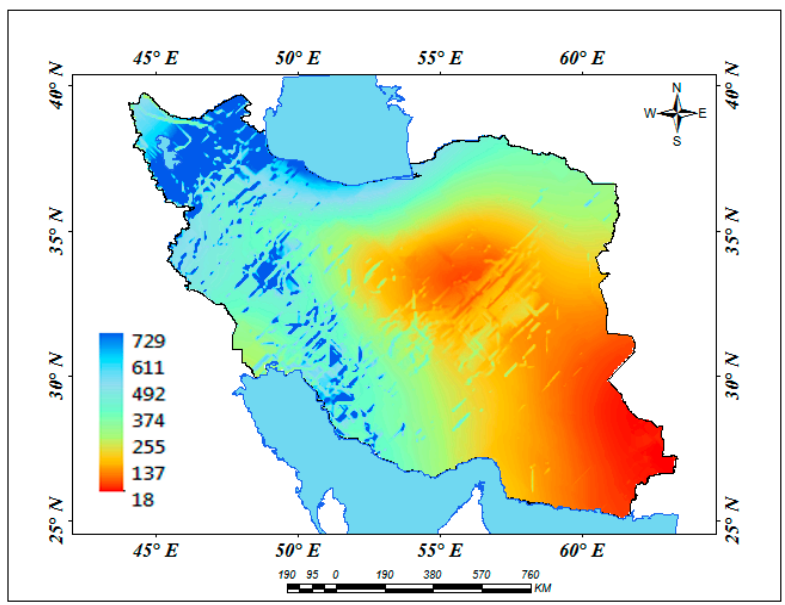

Figure 22. Forecasting of rainfall by using linear multi-regression.

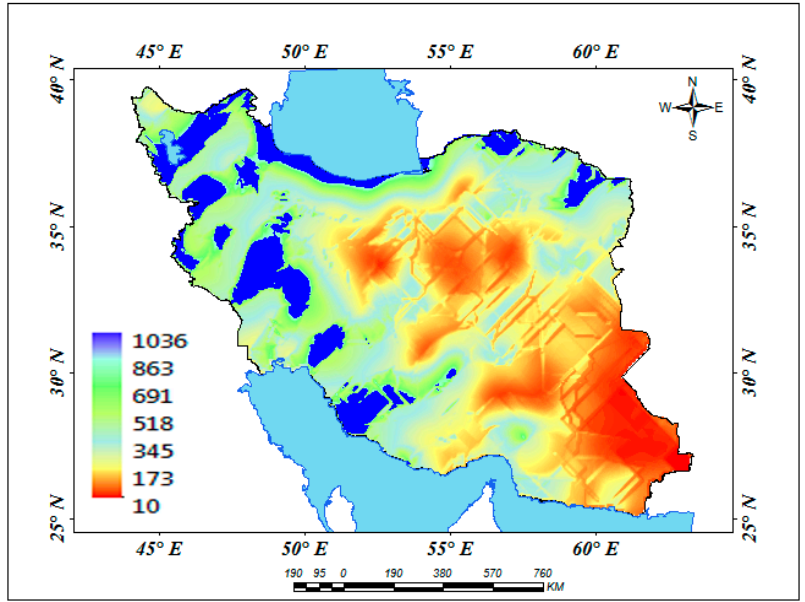

Figure 23. Forecasting of rainfall by using linear multi-regression.

Figure 23 points out high scattering that is mainly distributed in the north and northwestern part of Iran for all periods. In order to analyze the effects of temperature and elevation variables on rainfall with squared multiple $\mathrm{R}$ of about $66.4 \%$, a multi-regression equation with weights was computed. The temperature and elevation effects on rainfall should be analyzed. They were forecasted with the multi-regression model by using the following equation:

$$
\begin{gathered}
\text { Rainfall }=\text { 203.273 }+0.741 \text { winter }-1.329 \text { spring }+0.001 \text { summer }+1.762 \text { autumn }+ \\
\text { 7.769Jan.TEM }-16.5 \text { Feb.Tem }+1.5 \text { Mar.Tem }+11.467 \text { Apr.Tem }- \\
\text { 8.78May.Tem + 8.78June.Tem }- \text { 16.158July.Tem + 6.12Aug.Tem + 3.17Sept.Tem }- \text { 9.69Oct.Tem + } \\
\text { 7.36Nov.Tem }- \text { 0.428Annual.Tem }-0.018 \text { Elevation }
\end{gathered}
$$

where Tem is the temperature, winter is the winter temperature, spring is the spring temperature, summer is the summer temperature, autumn is the autumn temperature, Jan is the January month, Feb is the February month, Mar is the March month, ANNUAL is the annual temperature and Elevation is the elevation points. The results obtained for Equation 20 on the data of rainfall for any particular month, season, and annual period are presented in Figure 23. A spatial regression equation was estimated by using Equation 20 to analyze the rainfall spatial pattern variations with a rate of about $744.6 \mathrm{~mm}$ in Iran (Figure 23). The results obtained for equation 20 on data of rainfall for any particular month, season, and annual period are presented in Figure 23. Figure 23 points out high scattering that is mainly distributed in the north, west, and northwestern parts of Iran for all periods. Equations 
19 and 20 examine the relationship between temperature, elevation (monthly, seasonal and annual), and rainfall with a determination coefficient ( $R$-squared) of about $63.89 \%$ and $66.4 \%$. The impact of temperature and elevation on the rainfall during various periods is coordinated with a determination coefficient of $66.4 \%$. The determination coefficient also shows that the interaction effects are significant. The determination coefficient of models shows that the major difference of effect in $66.4 \%$ and $63.89 \%$ is not significant. The coefficient of determination shows that there is not a major difference between the temperature and the elevation on rainfall. Accordingly, it becomes clear that the temperature effect is more effective than elevation in Iran.

\subsubsection{Spatial Regression Analysis}

In this study, as a result of spatial autocorrelation between the temperature, elevation, DEM and rainfall, we applied the Ordinary Least Squares regression (OLS) as a global regression to analyze the relations between series and local patterns with three special features: (1) the evaluation and mapping of spatial structure in model errors (which may reveal the need for explicit spatial modelling); (2) partial regression analysis, using up to an order polynomial expansion of geographical coordinates; and (3) the calculation of the Akaike information criterion (AIC) for valuation of model fit. Table 8 displays the initial coefficients of the OLS model. According to Table 8, the F-statistics (F: 10.759, $P:<0.001)$ are all significant, indicating the presence of model significance. The Akaike's Information Criterion (AICc) statistics (2453.83) are also significant, indicating that this model is the most suitable model for the analyzed data.

Table 8. Results of the OLS model.

\begin{tabular}{|c|c|c|c|c|c|c|c|}
\hline \multicolumn{8}{|c|}{ Results for Rainfall as a Response Variable. Temperature, Elevation and DEM as Predictor Variables } \\
\hline \multirow{3}{*}{$\begin{array}{l}\text { Variable } \\
\text { Constant }\end{array}$} & \multirow{3}{*}{$\begin{array}{c}\text { Coefficient } \\
1235.539\end{array}$} & \multicolumn{4}{|c|}{$\begin{array}{l}\text { N: } 174, \text { R: } 0.399, \mathrm{R}^{2}: 0.16, \mathrm{R}^{2} \text { adj: } 0.145, F: 10.759, P:<0.001 \\
\quad \text { Akanke's Information Criterion (AICc) : } 2453.833\end{array}$} & \multirow{2}{*}{\multicolumn{2}{|c|}{$P$-Value }} \\
\hline & & Standard Coefficient & VIF & Standard Error & $t$ & & \\
\hline & & 0 & 0 & 161.709 & 7.64 & $<0.001$ & * \\
\hline Temperature & -34.802 & -0.579 & 2.273 & 6.377 & -5.457 & $<0.001$ & * \\
\hline DEM & -0.264 & -0.55 & 6.191 & 0.084 & -3.146 & 0.002 & * \\
\hline Elevation & 0.003 & 0.008 & 4.748 & 0.065 & 0.053 & 0.958 & \\
\hline & & $\begin{array}{r}\text { Condit } \\
\text { Mean of C } \\
\text { First Eigenve } \\
\text { Asterisks indicate sign }\end{array}$ & $\begin{array}{l}\text { Numb } \\
\text { elation } \\
\text { e divid } \\
\text { ant tes }\end{array}$ & $\begin{array}{l}.061 \\
x: 0.763 \\
\mathrm{~m}: 0.843 \\
\text { he series at } P<0.0\end{array}$ & & & \\
\hline
\end{tabular}

The t-test shows the statistical relationship between predictor variables (temperature, elevation and DEM) and the response variable (rainfall). However, the $p$-value for temperature and DEM $(<0.002)$ is smaller than the common alpha level of 0.05 , which reveals that it is statistically significant. In addition, the p-value for elevation (0.958) is greater than the common alpha level of 0.05, which shows that it is not statistically significant. Because OLS will provide the best estimates only when all of these assumptions are met, it is extremely important to test them and check the correlation between analysts using the Variance Inflation Factor (VIF). However, Variance Inflation Factors (VIF) measure how much the variance of the estimated OLS coefficients are inflated as compared to when the predictor variables are not linearly related. Use the guidelines to interpret the VIF: $1<$ VIF $<5$ moderately correlated; $5<\mathrm{VIF}<10$ highly correlated; and VIF values greater than 10 may indicate that multicollinearity is overly influencing OLS results. In Table 8, both the Joint F-Statistic and Joint Wald Statistic are measures of overall model statistical significance. The Joint F-Statistic (tests the normality of the errors) is trustworthy only when the Koenker (BP) statistic (Table 8) is not statistically significant. If the Koenker (BP) statistic is significant, you should consult the Joint Wald Statistic to determine the overall model significance. The null hypothesis for both of these tests indicates that the explanatory variables in the model are not effective. For a 95\% confidence level, a p-value (probability) is smaller than 0.05 and indicates a statistically significant model. Results obtained from a specified 
OLS model are trustworthy such as those obtained from R-Squared and Akaike's Information Criterion (AICc) measure fit/performance model and Joint $\mathrm{F}$ and Wald Statistics. Asterisk $\left(^{*}\right)$ indicates the overall model significance $(p<0.01)$; if the Koenker (BP) Statistic [f] is statistically significant, use the Wald Statistic to determine the overall model significance. Koenker (BP) Statistic: when this test is statistically significant $(p<0.01)$, the relationships modeled are not consistent (due to non-stationary); use Wald Statistic to determine the overall model significance. Jarque-Bera Statistic: when this test is statistically significant $(p<0.01)$, model predictions are biased (the residuals are not normally distributed). Bandwidth or Neighbors are the numbers of neighbors used for each local estimation and are perhaps the most important parameters for Geographically Weighted Regression. They control the degree of smoothing in the model. Residual Squares is the sum of the squared residuals in the model with the GWR model. The smaller this measure, the closer the fit of the GWR model to the observed data. This value is used in a number of other diagnostic measures. Effective Number value reflects an interchangeability between the variance of the fitted values and the bias in the coefficient estimates and is related to the choice of bandwidth. As the bandwidth approaches infinity, the geographic weights for every observation approach 1 , and the coefficient estimates will be very close to those for a global OLS model. For very large bandwidths, the effective number of coefficients approaches the actual number; local coefficient estimates will have a small variance; however, they will be quite biased. Conversely, as the bandwidth approaches zero, the geographic weights for every observation approach zero with the exception of the regression point itself. For extremely small bandwidths, the effective number of coefficients is the number of observations, and the local coefficient estimates will have a large variance but a low bias. The effective number is used to compute a number of diagnostic measures. Sigma is the square root of the normalized residual sum of squares, where the residual sum of squares is divided by the effective degrees of freedom of the residual. This is the estimated standard deviation for the residuals. Smaller values of this statistic are preferable. Sigma is used for AICc computations. AIC $c$ is the measure of model performance and is helpful for comparing different regression models. Taking into account the model complexity, the model with the lower AICc value provides a better fit to the observed data. If the AICc values for two models differ by more than 3, the model with the lower AIC $c$ is held to be better. Comparing the GWR AICc value to the OLS AICc value is one way to assess the benefits of moving from a global model (OLS) to a local regression model (GWR). R-Squared ( $\left.R^{2}\right)$ is a measure of goodness-of-fit. Its value varies from 0.0 to 1.0 , with higher values being preferable. $\mathrm{R}^{2}$ Adjusted is described above for the $\mathrm{R}^{2}$ value. This has the effect of compensating for the number of variables in a model, and consequently, the adjusted $R^{2}$ value is usually smaller than the $R^{2}$ value. In GWR, the effective number of degrees of freedom is a function of the bandwidth, so the adjustment may be quite marked in comparison to a global model such as OLS. For this reason, the AICc is preferred as a means of comparing models. The Joint F-Statistics (6.73) are also statistically significant $(0.0002<p<0.01)$ and Joint Wald Statistic $(29.12)$ is statistically significant $(0.000002<p<0.01)$ as the overall model. The Koenker (BP) Statistics (4.09) are consistent $(0.251<p<0.01)$ with the relationships modeled. The Jarque-Bera Statistics (940.61) are also the residuals $(0.00<P<0.01)$ not normally distributed (when the p-value for this test is small (smaller than 0.05 for a $95 \%$ confidence level); the residuals are not normally distributed, showing model misspecification. However, model residuals' estimates are not normally distributed for GWR analysis between temperature, DEM, elevation and rainfall. In addition, the mean of the correlation matrix is statistic for potential correlation coefficients between temperature, DEM, elevation and rainfall. When the mean of the correlation matrix is considerable (0.763), it reveals that the relationships between temperature, DEM, elevation and rainfall are statistically significant due to variation patterns. R-squared (coefficient of determination or $\mathrm{R}^{2}$ ) is a statistical measure of how close the temperature, DEM, elevation and rainfall are to the fitted regression line. It is the percentage of the response variable variation (rainfall) that is explained by a linear model. However, the $\mathrm{R}^{2}$ for the OLS model are not very high ( 0.16 or lower than $50 \%$ ). Figure 24 presents the Moran's I statistics of the OLS model. It shows that the Moran's I statistics (spatial effectiveness) present notable spatial variations for temperature, DEM, elevation and rainfall, indicating that the 
change point (about $6.3 \mathrm{~m}$ ) of the OLS model varies and increases with the distance. GWR (a local form of linear regression used to model spatially varying relationships) expands the OLS by combining spatial relationships; it is controlled by the kernel type, bandwidth method, distance, and number of neighbors parameters [22,48].

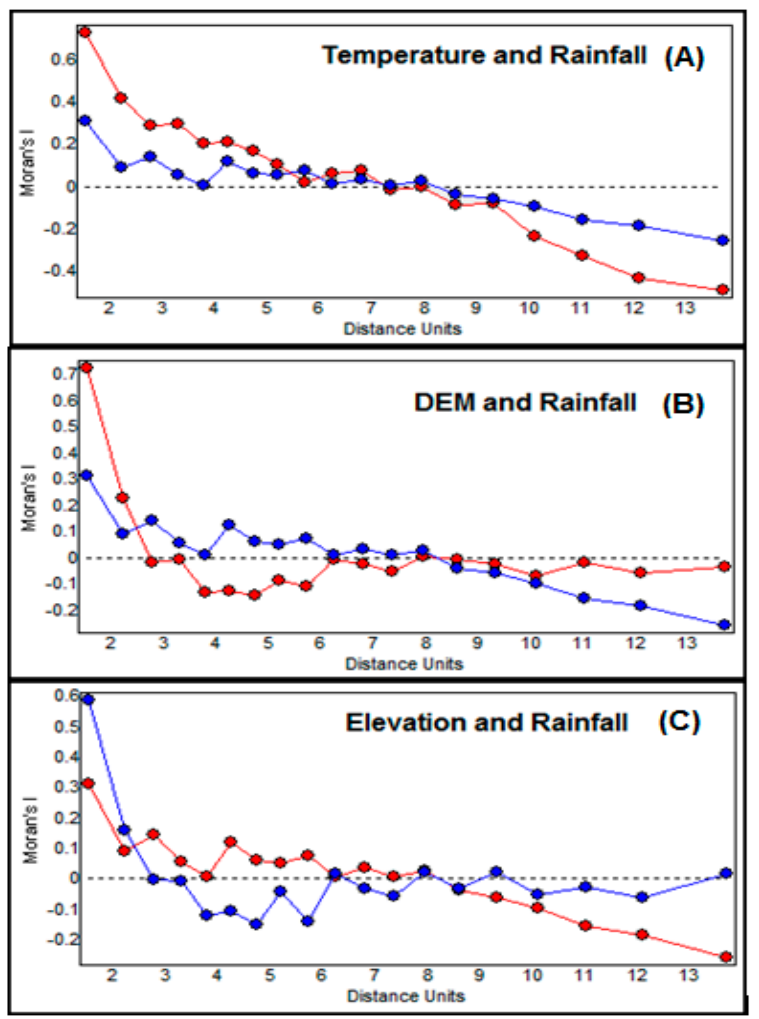

Figure 24. Illustrates forecasting of the Moran's I statistics for spatial effectiveness. There is relatively high Moran's $I$ of 0.25 in the first distance class, indicating that Type Moran's $I$ errors are biased. More importantly, there is a lack of explanation of richness at those short distances. (A) Temperature and rainfall; (B) DEM and rainfall; (C) Elevation and rainfall.

Table 9 displays the output of the GWR model for temperature, DEM, elevation and rainfall. The results for the GWR model are much better than those for the OLS model to predict the effectiveness of temperature, DEM, elevation to rainfall. The F-test and $R^{2}$ (GWR: 0.508 and OLS: 0.16 ) indicate that the AIC amount for the GWR model (GWR: 2437.084 and OLS: 2453.833) to analyze the effectiveness is more effective than to OLS model. The results of GWR present that the GWR is more suitable in analyzing and predicting the effectiveness of temperature, DEM, and elevation to rainfall.

Table 9. Results of OLS and GWR models.

\begin{tabular}{|c|c|c|c|c|c|c|}
\hline GWR & GWR & OLS & OLS & $p$-Value & $\begin{array}{c}\text { Significance } \\
\text { Level }\end{array}$ & Result \\
\hline \multirow{2}{*}{$\begin{array}{l}\text { Bandwidth } \\
\text { Residual } \\
\text { Squares }\end{array}$} & 7.875 & Multiple R-Squared & 0.106 & 0.0903 & $P<0.01$ & \multirow{4}{*}{$\begin{array}{l}\text { Model is not Fitted } \\
\text { is statistically } \\
\text { significant } \\
\text { is statistically } \\
\text { significant } \\
\text { The relationship } \\
\text { modeled are consistent } \\
\text { is statistically }\end{array}$} \\
\hline & $11,484,879.597$ & Joint F-Statistic & 6.7269 & 0.0002 & $P<0.01$ & \\
\hline $\begin{array}{l}\text { Effective } \\
\text { Number }\end{array}$ & 8.905 & Joint Wald Statistic & 29.121 & 0.000002 & $P<0.01$ & \\
\hline Sigma & 263.753 & Koenker (BP) Statistic & 4.093 & 0.251558 & $P<0.01$ & \\
\hline $\mathrm{R}^{2}$ & 0.2453 & $\mathrm{AICc}$ & 2464.561 & & $P<0.01$ & Model is Fitted \\
\hline \multirow[t]{2}{*}{$\mathrm{R}^{2}$ Adjusted } & 0.2092 & VIF & & Values(>7.5) & & \\
\hline & & $t$ & 0.376 & $P<0.01$ & $P<0.01$ & $\begin{array}{l}\text { is statistically } \\
\text { significant }\end{array}$ \\
\hline
\end{tabular}


Figure 25 shows the Moran's I statistics of the GWR model. It shows that the Moran's I statistics (spatial effectiveness) are significant model for spatial variations of temperature, DEM, elevation and rainfall, revealing that the change point (about $8 \mathrm{~m}$ ) of the GWR model varies and decreases with distance. Also, Local $\mathrm{R}^{2}$ is recorded to analyze the spatial variation relationships detected using GWR.

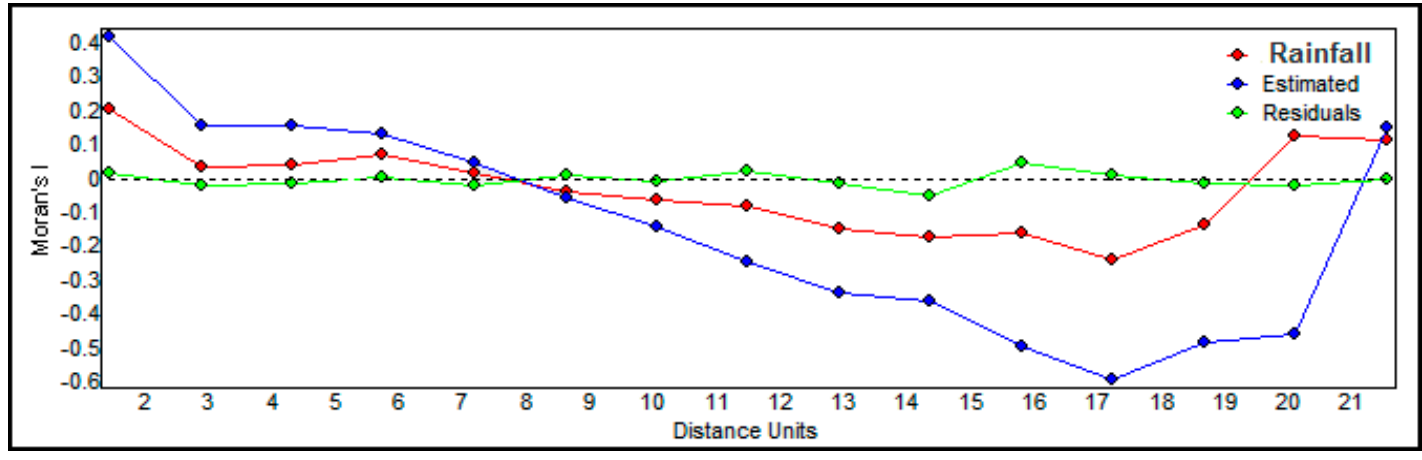

Figure 25. Moran's I statistics of the GWR model.

Figure 26 shows the local $\mathrm{R}^{2}$ of the GWR model. It shows that the local $\mathrm{R}^{2}$ (spatial effectiveness variability) is significantly decreased from north to south for spatial variations of temperature, DEM, elevation and rainfall, revealing that the change point (about 0.173) of the GWR model varies and decreases with the decrease of rainfall amounts and increases the spatial variability in Iran.

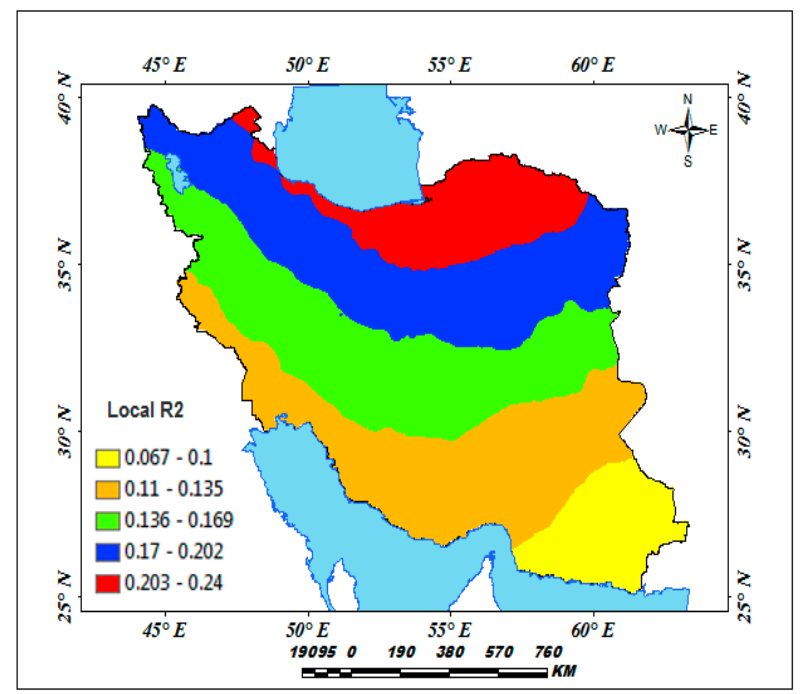

Figure 26. Local $R^{2}$ of the GWR model.

\subsection{Global and Local Spatial Autocorrelation Analysis}

In this study, the global spatial autocorrelation analysis of the correlation coefficients of temperature, elevation and rainfall for all stations was studied. The results specified for global Moran's I autocorrelation statistics for months, seasons, and annual period are regulated in Table 9. According to Table 9, Moran's I index computed for months, seasons, and annual periods individuate statistically significant clustered spatial patterns for all periods. Table 10 displays Moran's I index and related Moran's I scores for all studied stations in the monthly, seasonal and annual periods. Bajat et al. (2013) denote that a high Z score of Gi statistics develops when the spatial clustering is created by related but high values. If the spatial clustering is created by low values, the $Z$ score will tend to be highly negative $[49,54]$. Table 10 shows clustering patterns for all selective stations in 
all months, seasons and annual periods. The local spatial autocorrelation analysis of the correlation coefficients of temperature, elevation, and rainfall for all stations was computed. Therefore, the local Gi data is computed in all stations for monthly, seasonal and annual periods.

Table 10. Moran's I autocorrelation statistics in Iran.

\begin{tabular}{ccccc}
\hline Series & Moran's I & Z-Score & $p$-Value & Result \\
\hline January & 0.702 & 7.07 & 0.0000 & clustering of high values \\
February & 0.719 & 7.23 & 0.0000 & clustering of high values \\
clustering of high values \\
March & 0.732 & 7.36 & 0.0000 & clustering of high values \\
April & 0.784 & 7.87 & 0.0000 & clustering of high values \\
May & 0.835 & 8.37 & 0.0000 & clustering of high values \\
June & 0.794 & 7.79 & 0.0000 & clustering of high values \\
July & 0.813 & 8.17 & 0.0000 & clustering of high values \\
August & 0.839 & 8.43 & 0.0000 & clustering of high values \\
clustering of high values \\
clustering of high values \\
October & 0.823 & 8.27 & 0.0000 & clustering of high values \\
Devember & 0.784 & 7.88 & 0.0000 & clustering of high values \\
Winter & 0.732 & 7.36 & 0.0000 & clustering of high values \\
Spring & 0.667 & 6.72 & 0.0000 & clustering of high values \\
Summer & 0.722 & 7.27 & 0.0000 & clustering of high values \\
Autumn & 0.811 & 8.13 & 0.0000 & clustering of high values \\
Annual & 0.832 & 8.36 & 0.0000 & 0.0000 \\
\hline
\end{tabular}

Figure 27 displays the local Gi index and related Gi Z scores for all studied stations in the monthly, seasonal and annual periods. The red colored spots (hot spots) determine the clustering of high or spatial clusters of high (direct) correlations and the low Gi values (cold spots) determine the clustering of low or spatial clusters of low value (inverse) correlations (blue colored). With statistically significant positive $z$-scores, the larger the z-score is, the more intense the clustering of high values is (hot spot or red colored spots). For statistically significant negative $z$-scores, the smaller the $z$-score is, the more intense the clustering of low values is (cold spot or blue colored). The yellow colored spots (neutral spots or insignificant) determine the anechoic of clustering or spatial incognizant (no correlation). The red colored spots (hot spots) shows clustering of high (direct) correlations that are distributed in the west and southwest part Iran for the winter season and the months of January, February, March and December. The hot spots shows clustering of high (direct) correlations that are distributed in the in the northwestern part of Iran for the annual period for the spring season. The hot spots shows clustering of high (direct) correlations that are distributed in the in the southwestern part of the Caspian Sea for the annual period for the Autumn, and Summer seasons and June, July, August, September, October and November months.

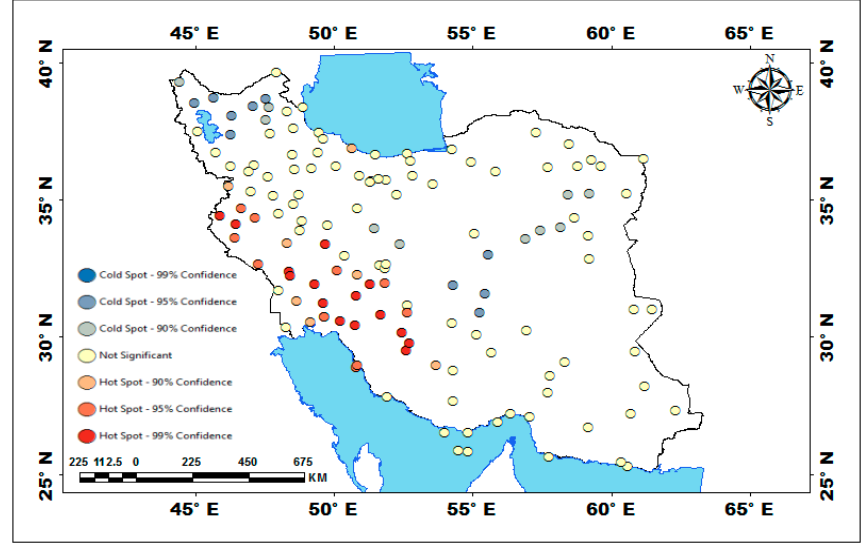

(1) January

Figure 27. Cont. 


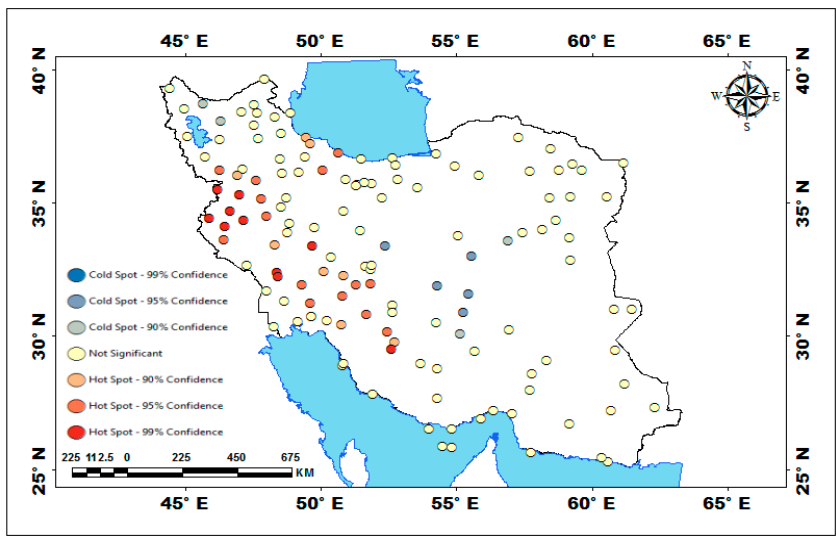

(2) February

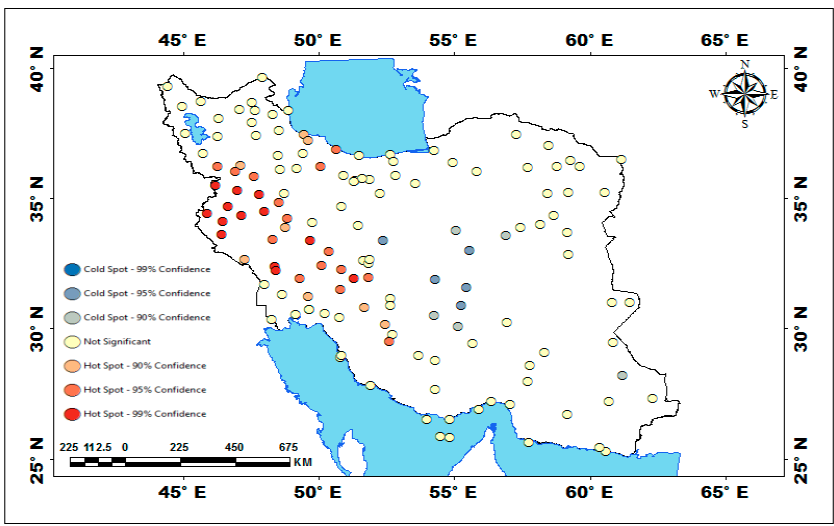

(3) March

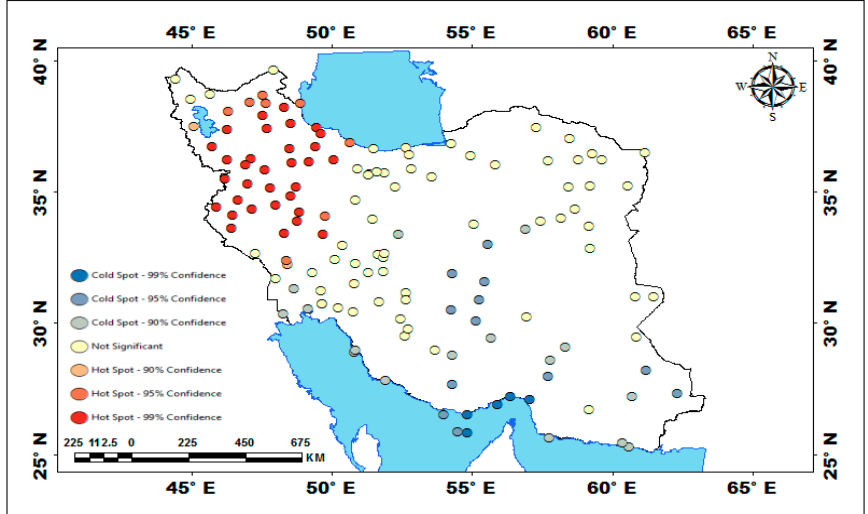

(4) April

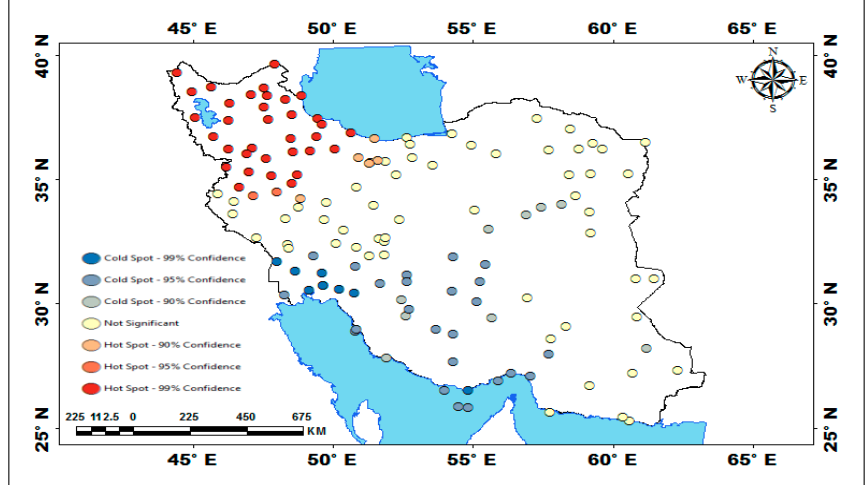

(5) May

Figure 27. Cont. 


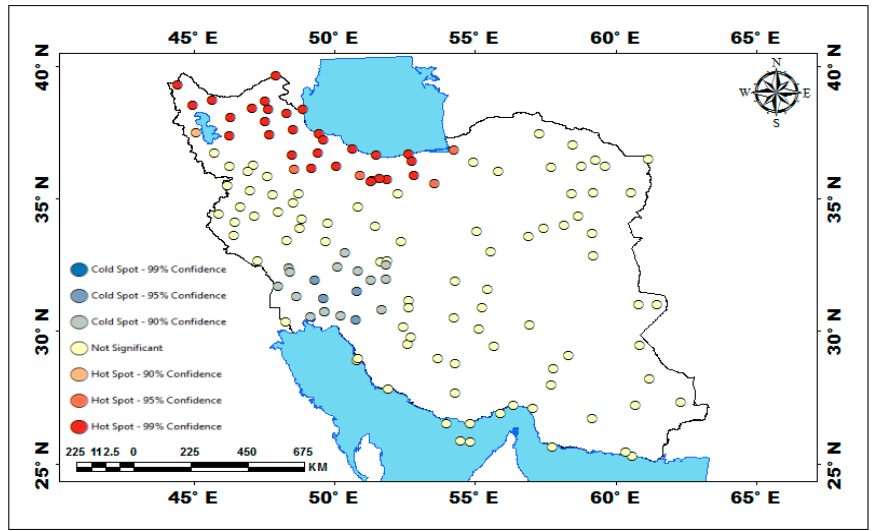

(6) June

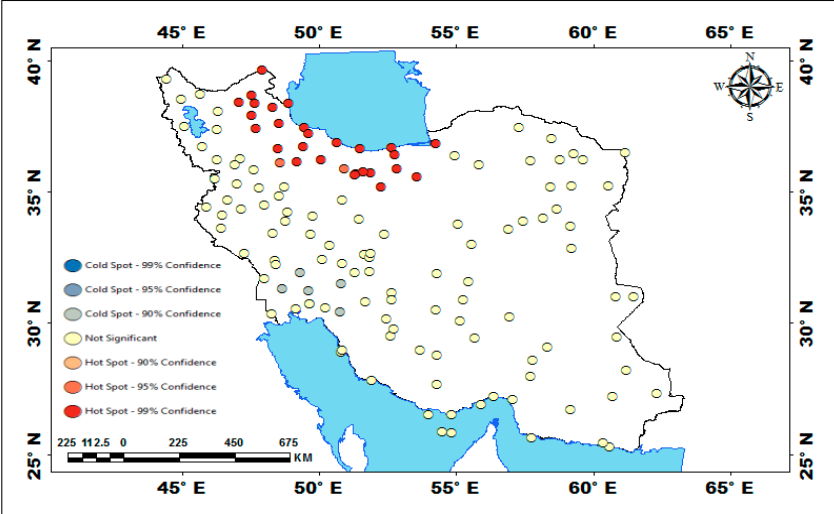

(7) July

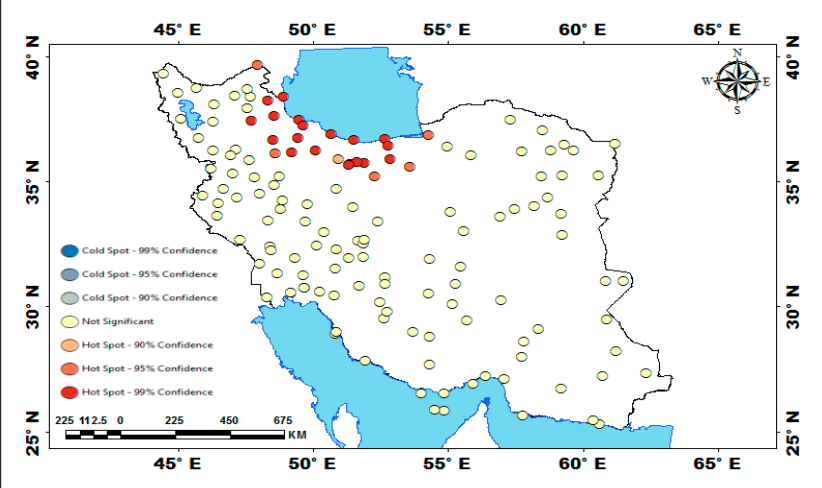

(8) August

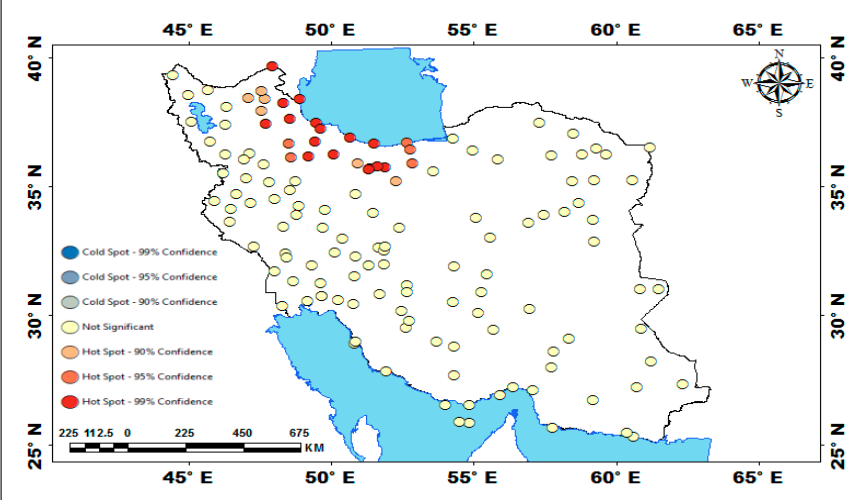

(9) September

Figure 27. Cont. 


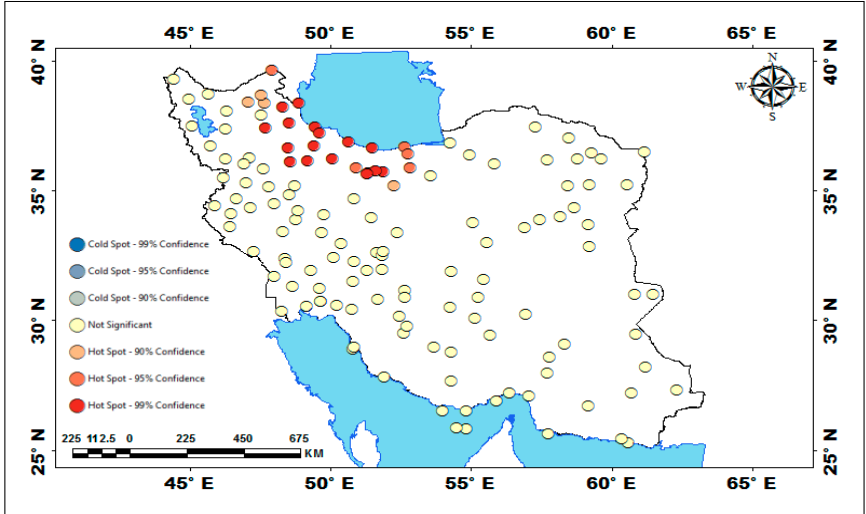

(10) October

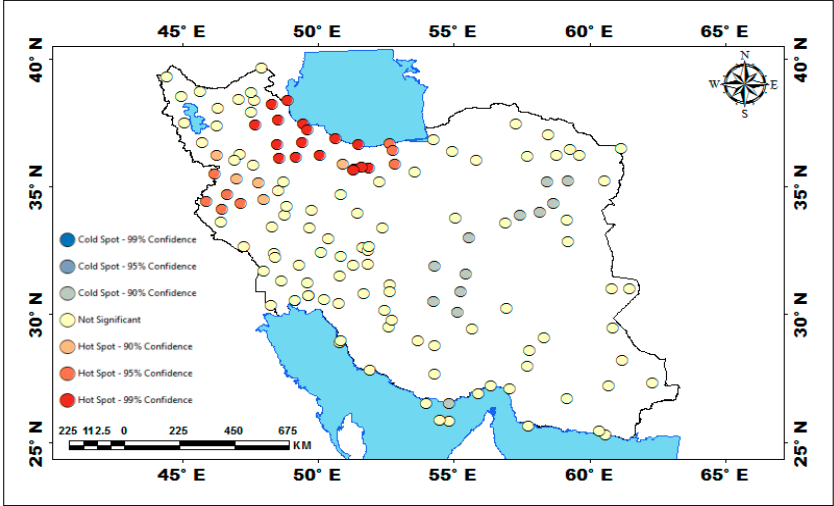

(11) November

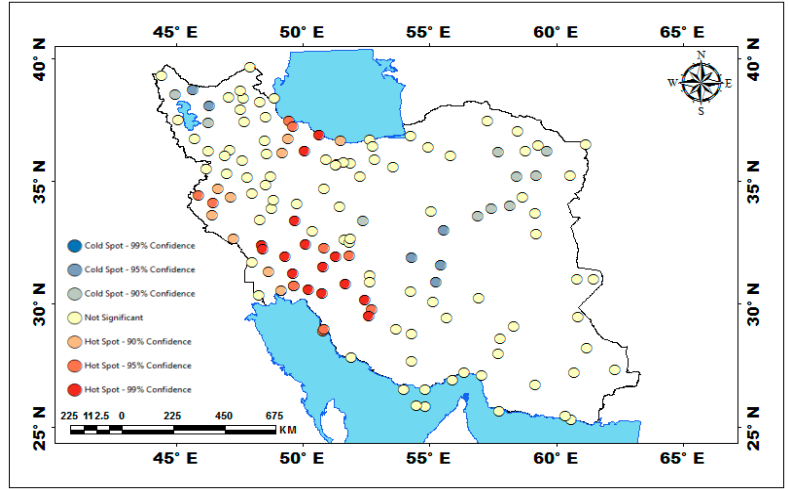

(12) December

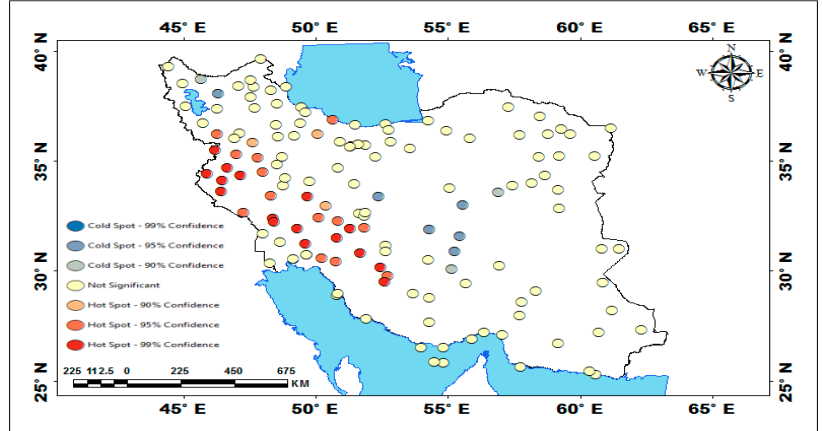

(13) Winter

Figure 27. Cont. 


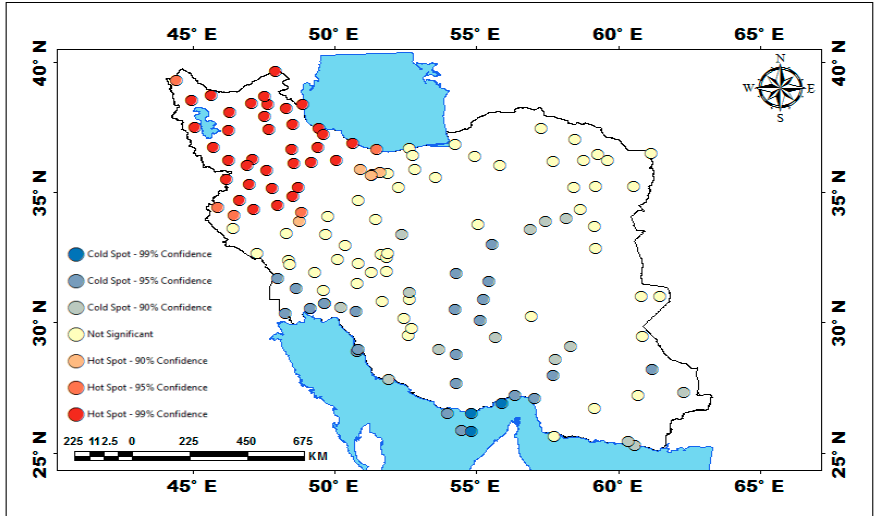

(14) Spring

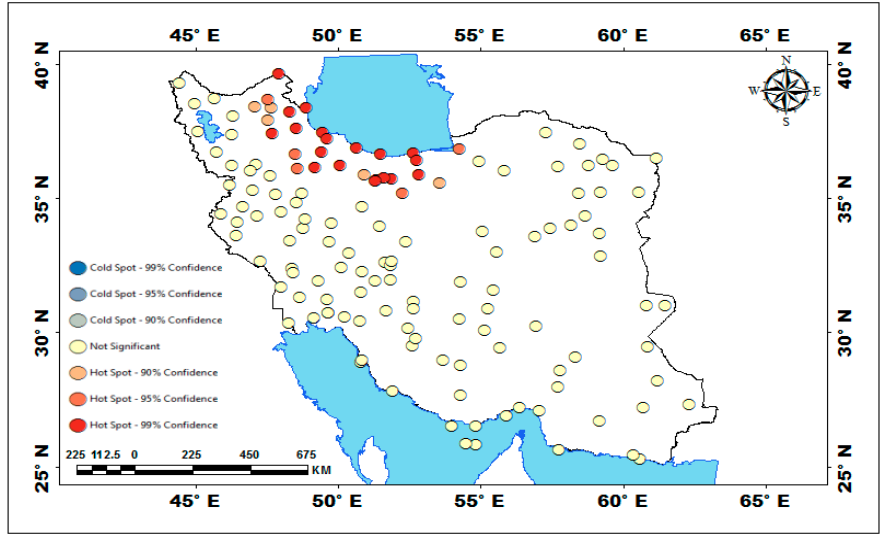

(15) Summer

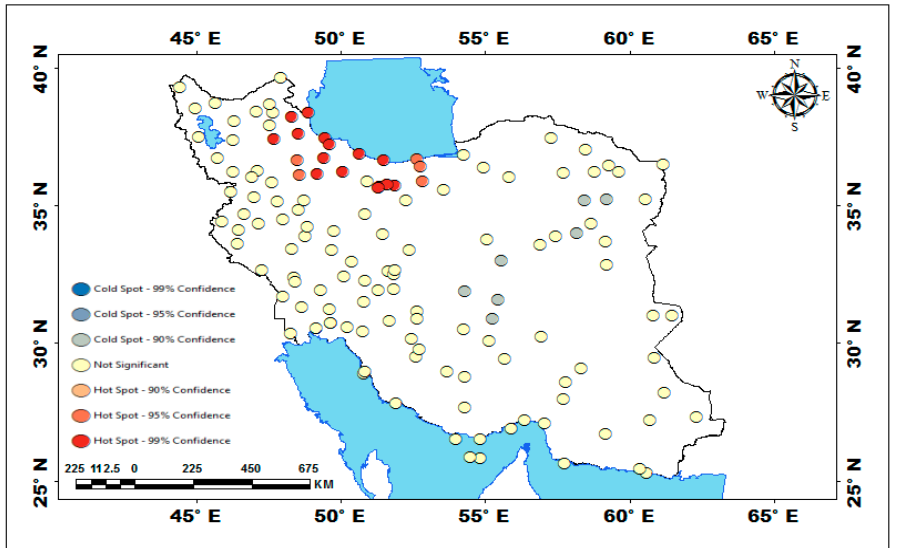

(16) Autumn

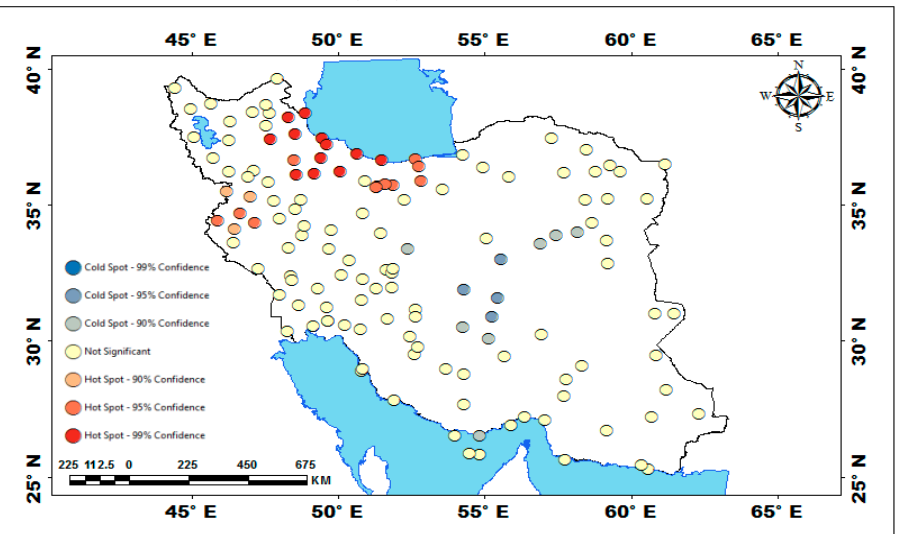

(17) Annual

Figure 27. Gi statistics calculated monthly (1-12), seasonally (13-16) and monthly (17). 


\section{Conclusions}

This study showed the relationships and effectiveness (causality) between temperature and topography (elevation and DEM) and their effects on rainfall in Iran during the period of 1975-2014 by using data from 174 stations and 39,055 points. The temporal correlation coefficient between the rainfall, topography and temperature amounts for all stations was computed. The result showed a negative correlation (between rainfall and temperature except for January and December). As shown in the results, the spatial correlation coefficient between the rainfall, topography and temperature amounts for all stations indicated a strong spatial irregularity between the elevation, temperature and rainfall, whereas between the DEM and rainfall, a moderate spatial irregularity was displayed. In addition, the effectiveness between temperature and topography (elevation and DEM) on rainfall was observed in Iran. It was found that there was weak negative effectiveness between the elevation, DEM, monthly temperature and annual rainfall in Iran; also, significant negative effectiveness was noticed between the DEM, elevation and monthly temperature $\left(0.83<\mathrm{R}^{2}<0.99\right)$ on annual rainfall. These spatial patterns are statistically significant clustered spatial patterns for all periods. Moran's I index analysis indicated that there is similar spatial variability between rainfall, temperature, and elevation amounts in Iran. Spatially, the highest amounts of clusters were in the west and southwest for the winter season and the months of January, February, March and December; in southwestern Caspian sea for the annual period, Autumn and Summer seasons and June, July, August, September, October, and November months; and for May and April months, in northwest Iran. Monthly temperature has an impact on the variability of the rainfall patterns, especially in northern regions of Iran. Future studies should aim to achieve a better understanding of the effectiveness of control factors on Iran's rainfall; the number of monitoring methods needs to be increased. Moreover, in order to trace the modeling of rainfall variability and rainfall variation, the interior and exterior factors affecting rainfall in Iran should be combined.

Acknowledgments: This research was supported by research management in PayameNoor University. We also thank PayameNoor management and the research committee of PayameNoor University.

Conflicts of Interest: The author declares no conflict of interest.

\section{References}

1. Akbary, M. Combinatory Mediterranean-Sudanese systems role in the occurrence of heavy rainfalls (case study: South west of Iran). Meteorol. Atmos. Phys. 2015, 127, 675-683. [CrossRef]

2. Alijani, B.; O'Brien, J.; Yarnal, B. Spatial analysis of precipitation intensity and concentration in Iran. Theor. Appl. Climatol. 2008, 94, 107-124. [CrossRef]

3. Ansari, S.M.; Kale, K. Methods for Crime Analysis Using GIS. Int. J. Sci. Eng. Res. 2014, 5, 1330-1336.

4. Anselin, L.; Bera, A.K. Spatial dependence in linear regression models with an introduction to spatial econometrics. Stat. Textb. Monogr. 1998, 155, 237-290.

5. Asong, Z.E.; Khaliq, M.N.; Wheater, H.S. Regionalization of precipitation characteristics in the Canadian Prairie Provinces using large-scale atmospheric covariates and geophysical attributes. Stoch. Environ. Res. Risk Assess. 2015, 29, 875-892. [CrossRef]

6. Azar, A.G.R.; Ghanavati, M. Path-Structural Modeling in Management; Neghah Danesh Press: Tehran, Iran, 2012.

7. Bajat, B.; Pejović, M.; Luković, J.; Manojlović, P.; Ducić, V.; Mustafić, S. Mapping average annual precipitation in Serbia (1961-1990) by using regression kriging. Theor. Appl. Climatol. 2013, 112, 1-13. [CrossRef]

8. Cahn, M.; Hummel, J.; Brouer, B. Spatial analysis of soil fertility for site-specific crop management. Soil Sci. Soc. Am. J. 1994, 58, 1240-1248. [CrossRef]

9. Cai, X.; Wang, D. Spatial autocorrelation of topographic index in catchments. J. Hydrol. 2006, 328, 581-591. [CrossRef]

10. Chin, W.W. The partial least squares approach to structural equation modeling. Mod. Methods Bus. Res. 1998, 295, 295-336. 
11. Chin, W.W. Frequently asked questions-partial least squares and PLS-graph. Available online: http: //discnt.cba.uh.edu/chin/plsfaq.htm (accessed on 6 October 2005).

12. Clifford, P.; Richardson, S.; Hémon, D. Assessing the significance of the correlation between two spatial processes. Biometrics 1989, 45, 123-134. [CrossRef] [PubMed]

13. Cressie, N. Statistics for Spatial Data; Wiley: Hoboken, NJ, USA, 2015.

14. Di Piazza, A.; Conti, F.L.; Noto, L.V.; Viola, F.; La Loggia, G. Comparative analysis of different techniques for spatial interpolation of rainfall data to create a serially complete monthly time series of precipitation for Sicily, Italy. Int. J. Appl. Earth Obs. Geoinf. 2011, 13, 396-408. [CrossRef]

15. Dobesch, H.; Dumolard, P.; Dyras, I. Spatial Interpolation for Climate Data; ISTE: Wiltshire, UK, 2010.

16. Dourte, D.R.; Fraisse, C.W.; Bartels, W.-L. Exploring changes in rainfall intensity and seasonal variability in the Southeastern U.S.: Stakeholder engagement, observations, and adaptation. Clim. Risk Manag. 2015, 7, 11-19. [CrossRef]

17. Duan, P.; Qin, L.; Wang, Y.; He, H. Spatial pattern characteristics of water footprint for maize production in Northeast China. J. Sci. Food Agric. 2016, 96, 561-568. [CrossRef] [PubMed]

18. Dürre, A.; Vogel, D. Asymptotics of the two-stage spatial sign correlation. J. Multivar. Anal. 2016, 144, 54-67. [CrossRef]

19. El Osta, M.M.; Masoud, M.H. Implementation of a hydrologic model and GIS for estimating Wadi runoff in Dernah area, Al Jabal Al Akhadar, NE Libya. J. Afr. Earth Sci. 2015, 107, 36-56. [CrossRef]

20. ESRI. Geostatistical Analyst (ArcGIS10.3); ESRI: Redlands, CA, USA, 2014.

21. ESRI. Spatial Statistics Tools, ArcGIS Geostatistical Analyst, ArcMap 10.3; ESRI: Redlands, CA, USA, 2014.

22. ESRI. Spatial Statistics Tools (ArcGIS10.3); ESRI: Redlands, CA, USA, 2016.

23. Etemadi, H.; Samadi, S.Z.; Sharifikia, M.; Smoak, J. Assessment of climate change downscaling and non-stationarity on the spatial pattern of a mangrove ecosystem in an arid coastal region of southern Iran. Theor. Appl. Climatol. 2016, 126, 35-49. [CrossRef]

24. Fan, C.; Myint, S. A comparison of spatial autocorrelation indices and landscape metrics in measuring urban landscape fragmentation. Landsc. Urban Plan. 2014, 121, 117-128. [CrossRef]

25. Fischer, M.M.; Getis, A. Handbook of Applied Spatial Analysis: Software Tools, Methods and Applications; Springer: Berlin/Heidelberg, Germany, 2009.

26. Ghajarnia, N.; Liaghat, A.; Daneshkar Arasteh, P. Comparison and evaluation of high resolution precipitation estimation products in Urmia Basin-Iran. Atmos. Res. 2015, 158, 50-65. [CrossRef]

27. Goovaerts, P. Geostatistics for Natural Resources Evaluation; Oxford University Press: Oxford, UK, 1997.

28. Götz, O.; Liehr-Gobbers, K.; Krafft, M. Evaluation of Structural Equation Models Using the Partial Least Squares (PLS) Approach. In Handbook of Partial Least Squares: Concepts, Methods and Applications; Esposito Vinzi, V., Chin, W.W., Henseler, J., Wang, H., Eds.; Springer: Berlin/Heidelberg, Germany, 2010; pp. 691-711.

29. Griffié, J.; Boelen, L.; Burn, G.; Cope, A.P.; Owen, D.M. Topographic prominence as a method for cluster identification in single-molecule localisation data. J. Biophotonics 2015, 8, 925-934. [CrossRef] [PubMed]

30. Hair, J.F., Jr.; Hult, G.T.M.; Ringle, C.; Sarstedt, M. A Primer on Partial Least Squares Structural Equation Modeling (PLS-SEM); SAGE Publications Inc.: Thousand Oaks, CA, USA, 2014.

31. Hedberg, E.C.; Ayers, S. The power of a paired t-test with a covariate. Soc. Sci. Res. 2015, 50, $277-291$. [CrossRef] [PubMed]

32. Hengl, T. A Practical Guide to Geostatistical Mapping; Office for Official Publications of the European Communities: Luxembourg, Luxembourg, 2009.

33. Henseler, J.; Sarstedt, M. Goodness-of-fit indices for partial least squares path modeling. Comput. Stat. 2013, 28, 565-580. [CrossRef]

34. Hino, M.; Nadaoka, K. Mathematical derivation of linear and nonlinear runoff kernels. Water Resour. Res. 1979, 15, 918-928. [CrossRef]

35. Hoell, A.; Shukla, S.; Barlow, M.; Cannon, F.; Kelley, C.; Funk, C. The Forcing of Monthly Precipitation Variability over Southwest Asia during the Boreal Cold Season. J. Clim. 2015, 28, 7038-7056. [CrossRef]

36. IPCC Climate Change, 2013. The physical science basis. Summary for policymakers. In Contribution of Working Group I to the Fifth Assessment Report of the Intergovernmental Panel on Climate Change; Cambridge University Press: Cambridge, UK, 2013; p. 18.

37. Javari, M. A Study of Impacts of Temperature Components on Precipitation in Iran Using SEM-PLS-GIS. Earth Sci. Clim. Chang. 2015, 3, 1-14. 
38. Javari, M. Spatial-temporal variability of seasonal precipitation in Iran. Open Atmos. Sci. J. $2016,10$. [CrossRef]

39. Javari, M. Trend and Homogeneity Analysis of Precipitation in Iran. Climate 2016, 4, 44. [CrossRef]

40. Johnston, K.; Ver Hoef, J.M.; Krivoruchko, K.; Lucas, N. Using ArcGIS Geostatistical Analyst; ESRI: Redlands, CA, USA, 2001.

41. Joshi, S.; Kumar, K.; Joshi, V.; Pande, B. Rainfall variability and indices of extreme rainfall-analysis and perception study for two stations over Central Himalaya, India. Nat. Hazards 2014, 72, 361-374. [CrossRef]

42. Júnior, V.V.; Carvalho, M.P.; Dafonte, J.; Freddi, O.S.; Vidal Vázquez, E.; Ingaramo, O.E. Spatial variability of soil water content and mechanical resistance of Brazilian ferralsol. Soil Tillage Res. 2006, 85, 166-177. [CrossRef]

43. Kendall, M.G. Rank Correlation Methods, 4th ed.; Charles Griffin: London, UK, 1975.

44. Khalili, K.; Tahoudi, M.; Mirabbasi, R.; Ahmadi, F. Investigation of spatial and temporal variability of precipitation in Iran over the last half century. Stoch. Environ. Res. Risk Assess. 2016, 30, 1205-1221. [CrossRef]

45. Kuletz, K.J.; Ferguson, M.C.; Hurley, B.; Gall, A.E.; Labunski, E.A.; Morgan, T.C. Seasonal spatial patterns in seabird and marine mammal distribution in the eastern Chukchi and western Beaufort seas: Identifying biologically important pelagic areas. Prog. Oceanogr. 2015, 136, 175-200. [CrossRef]

46. Leguina, A. A primer on partial least squares structural equation modeling (PLS-SEM). Int. J. Res. Method Educ. 2015, 38, 220-221. [CrossRef]

47. Little, T.D. The Oxford Handbook of Quantitative Methods, Volume 1: Foundations; Oxford University Press: England, UK, 2013.

48. Lohmöller, J.-B. Latent Variable Path Modeling with Partial Least Squares; Springer: Berlin/Heidelberg, Germany, 2013.

49. Luković, J.; Blagojevć, D.; Kilibarda, M.; Bajat, B. Spatial pattern of North Atlantic Oscillation impact on rainfall in Serbia. Spat. Stat. 2015, 14, 39-52. [CrossRef]

50. Mertens, W.; Pugliese, A.; Recker, J. Models with Latent Concepts and Multiple Relationships: Structural Equation Modeling. In Quantitative Data Analysis: A Companion for Accounting and Information Systems Research; Springer: Berlin/Heidelberg, Germany, 2017; pp. 37-59.

51. Modarres, R.; Sarhadi, A. Statistically-based regionalization of rainfall climates of Iran. Glob. Planet. Chang. 2011, 75, 67-75. [CrossRef]

52. Odeha, I.; McBratney, A.; Chittleborough, D. Spatial prediction of soil properties from landform attributes derived from a digital elevation model. Geoderma 1994, 63, 197-214. [CrossRef]

53. Ogungbenro, S.B.; Morakinyo, T.E. Rainfall distribution and change detection across climatic zones in Nigeria. Weather Clim. Extremes 2014, 5, 1-6. [CrossRef]

54. Oliver, M.A.; Webster, R. A tutorial guide to geostatistics: Computing and modelling variograms and kriging. Catena 2014, 113, 56-69. [CrossRef]

55. Paixao, E.; Mirza, M.M.Q.; Shephard, M.W.; Auld, H.; Klaassen, J.; Smith, G. An integrated approach for identifying homogeneous regions of extreme rainfall events and estimating IDF curves in Southern Ontario, Canada: Incorporating radar observations. J. Hydrol. 2015, 528, 734-750. [CrossRef]

56. Peeters, A.; Zude, M.; Käthner, J.; Ünlü, M.; Kanber, R.; Hetzroni, A.; Gebbers, R.; Ben-Gal, A. Getis-Ord's hot- and cold-spot statistics as a basis for multivariate spatial clustering of orchard tree data. Comput. Electron. Agric. 2015, 111, 140-150. [CrossRef]

57. Phillips, D.L.; Dolph, J.; Marks, D. A comparison of geostatistical procedures for spatial analysis of precipitation in mountainous terrain. Agric. Forest Meteorol. 1992, 58, 119-141. [CrossRef]

58. Ramirez, M.C.V.; de Campos Velho, H.F.; Ferreira, N.J. Artificial neural network technique for rainfall forecasting applied to the Sao Paulo region. J. Hydrol. 2005, 301, 146-162. [CrossRef]

59. Rosemary, F.; Vitharana, U.W.A.; Indraratne, S.P.; Weerasooriya, R.; Mishra, U. Exploring the spatial variability of soil properties in an Alfisol soil catena. Catena 2017, 150, 53-61. [CrossRef]

60. Sayemuzzaman, M.; Jha, M.K. Seasonal and annual precipitation time series trend analysis in North Carolina, United States. Atmos. Res. 2014, 137, 183-194. [CrossRef]

61. Sebastian, T.; Anandan, S.; Jeyaseelan, V.; Jeyaseelan, L.; Ramanathan, K.; Veeraraghavan, B. Role of seasonality and rainfall in Vibrio cholerae infections: A time series model for 11 years surveillance data. Clin. Epidemiol. Glob. Health 2015, 3, 144-148. [CrossRef] 
62. Shekhar, S.; Xiong, H. Encyclopedia of GIS; Springer: Berlin/Heidelberg, Germany, 2007.

63. Singer, M.; Krivobokova, T.; Munk, A.; de Groot, B. Partial least squares for dependent data. Biometrika 2016, 103, 351-362. [CrossRef] [PubMed]

64. Sorooshian, S. Structural Equation Modeling Algorithm and Its Application in Business Analytics. In Organizational Productivity and Performance Measurements Using Predictive Modeling and Analytics; IGI Global: Hershey, PA, USA, 2017; pp. 17-39.

65. Su, S.; Lei, C.; Li, A.; Pi, J.; Cai, Z. Coverage inequality and quality of volunteered geographic features in Chinese cities: Analyzing the associated local characteristics using geographically weighted regression. Appl. Geogr. 2017, 78, 78-93. [CrossRef]

66. Tayyebi, A.; Darrel Jenerette, G. Increases in the climate change adaption effectiveness and availability of vegetation across a coastal to desert climate gradient in metropolitan Los Angeles, CA, USA. Sci. Total Environ. 2016, 548, 60-71. [CrossRef] [PubMed]

67. Tenenhaus, M.; Mauger, E.; Guinot, C. Use of ULS-SEM and PLS-SEM to measure a group effect in a regression model relating two blocks of binary variables. In Handbook of Partial Least Squares; Springer: Berlin/Heidelberg, Germany, 2010; pp. 125-140.

68. Vinzi, V.E.; Chin, W.W.; Henseler, J.; Wang, H. Handbook of Partial Least Squares: Concepts, Methods and Applications; Springer: Berlin/Heidelberg, Germany, 2010.

69. Von Storch, H.; Zwiers, F.W. Statistical Analysis in Climate Research; Citeseer: University Park, PA, USA, 2002.

70. Wang, H.; Cheng, Q.; Zuo, R. Quantifying the spatial characteristics of geochemical patterns via GIS-based geographically weighted statistics. J. Geochem. Explor. 2015, 157, 110-119. [CrossRef]

71. Wikle, C.K. Modeling Hydrologic Change: Statistical Methods. Technometrics 2003, 45, 366-367. [CrossRef]

72. Wilkinson, L. Statistical methods in psychology journals: Guidelines and explanations. Am. Psychol. 1999, 54, 594. [CrossRef]

73. Wong, W.; Lee, J. Statistical analysis of geographic information with ArcView GIS and ArcGIS; Wiley: Hoboken, NJ, USA, 2005.

74. Woody, J. Time series regression with persistent level shifts. Stat. Probab. Lett. 2015, 102, 22-29. [CrossRef]

(C) 2017 by the author. Licensee MDPI, Basel, Switzerland. This article is an open access article distributed under the terms and conditions of the Creative Commons Attribution (CC BY) license (http:/ / creativecommons.org/licenses/by/4.0/). 